\title{
D. Viertes Kapitel: Untersuchungshaft
}

Die Rechtsprechung des Bundesverfassungsgerichts zum Untersuchungshaftvollzug bezieht sich größtenteils auf die Rechtslage vor dem Übergang der Gesetzgebungskompetenz für das Rechts des Untersuchungshaftvollzuges auf die Länder mit der am 1. September 2009 in Kraft getretenen Neufassung des Art. 74 GG $^{351}$ und den in der Folge eingetretenen Änderungen im einfachen Bundes- und Landesrechts (Gesetz zur Neuregelung des Untersuchungshaftrechts ${ }^{352}$ und landesgesetzliche Regelungen des Untersuchungshaftvollzuges; s. aber, auf diese Änderungen Bezug nehmend, BVerfGK 19, $326<334>$; auf der Grundlage des gem. § 13 EGStPO übergangsweise weitergeltenden $\S 119$ Abs. 3 StPO ergangen BVerG II/3, Beschluss vom 22.7.2010 - 2 BvR 1528/10 -, juris). Dementsprechend können Entscheidungsinhalte der Sache nach überholt sein. Unter anderem ist jeweils zu prüfen, ob verfassungsrechtliche Folgerungen, die aus einer bestimmten Beschaffenheit des einfachen Rechts, wie etwa dem generalklauselartigen Charakter des $\S 119$ Abs. 3 StPO a.F., gezogen wurden, auch unter der neuen Rechtslage zu ziehen sind.

\section{Allgemeines}

\section{Verfassungsrelevante Unterschiede zum Strafvollzug}

Zwar gibt es verfassungsrechtliche Anforderungen, die unterschiedslos für den Vollzug von Straf- und Untersuchungshaft gelten (s. z.B. zum Schutz einer „beleidigungsfreien Sphäre“ in der brieflichen Kommunikation ausdrücklich BVerfGE 90, $255<262>$ ). Bereichsweise wirken sich dagegen Unterschiede zwischen Straf- und Untersuchungshaft auf das Ausmaß der vom Gefangenen hinzunehmenden Einschränkungen aus.

351 Gesetz zur Änderung des Grundgesetzes (Artikel 22, 23, 33, 52, 72, 73, 74, 74a, 75, 84, 85, 87c, 91a, 91b, 93, 98, 104a, 104b, 105, 107, 109, 125a, 125b, 125c, 143c), vom 28.8.2006, BGB1 I S. 2034. 
Die Untersuchungshaft ist weder eine Strafe (BVerfGE 109, 133 $<175>$ ) noch strafähnlich (BVerfGE 110, $1<14>$ ). Bis zur rechtskräftigen Verurteilung, und daher auch während der Dauer der Untersuchungshaft, gilt die Unschuldsvermutung (BVerfGE 109, $133<175>$; näher unten 4.).

Bei der Prüfung der Verhältnismäßigkeit von Eingriffen fällt demgemäß einerseits zugunsten Untersuchungsgefangener ins Gewicht, dass sie noch nicht rechtskräftig verurteilt, sondern aufgrund bloßen Verdachts inhaftiert sind. So verbietet es sich, die im Strafvollzug geltenden Maßgaben für die Zulässigkeit von Durchsuchungen, die mit einer Inspektion normalerweise bedeckter Körperöffnungen verbunden sind, schematisch auf den Untersuchungshaftvollzug zu übertragen.

- „Hier verschafft schon der Umstand, dass Untersuchungshaft nicht auf der Grundlage rechtskräftiger Verurteilung, sondern auf der Grundlage bloßen Verdachts verhängt wird (vgl. BVerfGE 15, $288<295>$; 34, 369 $<379>$; BVerfG, Beschluss der 2. Kammer des Zweiten Senats vom 10. Januar 2008 - 2 BvR 1229/07 - www.bverfg.de), den Belangen des Gefangenen, die in die Prüfung der Verhältnismäßigkeit grundrechtseingreifender Maßnahmen einzustellen sind, besonderes Gewicht. Schon von daher verbietet sich eine schematische Übertragung von für den Strafvollzug geltenden Maßgaben. Der Verweis auf Nr. 76 UVollzO (zur fehlenden rechtlichen Außenwirkung vgl. BVerfGE 15, $288<294>$; 34, $369<379>$ ) in Verbindung mit $\S 84$ StVollzG ist deshalb nicht geeignet, eine ausnahmslose Anordnung von Durchsuchungen mit Inspektion von üblicherweise bedeckten Körperöffnungen bei Aufnahme in die Untersuchungshaft zu rechtfertigen." ${ }^{\text {"353 }}$

Zudem sind die besonderen mit der Untersuchungshaft verbundenen psychischen Belastungen zu berücksichtigen (BVerfGK 13, $163<169$ f.>, s.u. D.X.; s. auch BVerfGK 20, $93<105>$ ).

Andererseits kann eine vollzugliche Schlechterstellung von Untersuchungsgefangen im Verhältnis zu Strafgefangenen hinzunehmen sein, weil die Sicherung des Zwecks der Untersuchungshaft sie erfordert. Inwieweit es geboten ist, mittels Personalaufwand solche Schlechterstellungen zu vermeiden, hängt von der Angemessenheit des Personalaufwandes nach Aufwand und Erfolg, auch im Verhältnis zur Situation im Straf-

353 BVerfGK 17, 9 (16); zur Notwendigkeit der - nicht notwendigerweise durchschlagenden - Berücksichtigung des Gesichtspunkts der noch nicht vorliegenden rechtskräftigen Verurteilung s. auch BVerfGK 20, 93 (100). 
vollzug, ab. Die Beurteilung der Zumutbarkeit von Einschränkungen kann daher auch eine Betrachtung der Angemessenheit der Verteilung der personellen Ressourcen im Verhältnis von Straf- und Untersuchungshaftvollzug einschließen (BVerfGK 20, $93<105>$, s. Auszug im Abschnitt zu den Aufschlusszeiten, D.III.; allg. zum Problem der Ressourcenknappheit im Vollzug s.o. A.VI.).

Für die Beurteilung der Zumutbarkeit von Beschränkungen spielt auch die im Verhältnis zur Strafhaft typischerweise nur kurze Dauer der Untersuchungshaft eine Rolle; daher die Übertragbarkeit der Standards für die Mindestgröße von Hafträumen (jedenfalls) in den dieser Typik entsprechenden Fällen (BVerfG II/2, Beschluss vom 19.10.1993 - 2 BvR 1778/93 -, juris; näher unten, D.X.)

Unterschiede in der verfassungsrechtlichen Zulässigkeit von Eingriffen in die Rechte von Untersuchungs- und Strafgefangenen können sich außerdem aus der einfachgesetzlichen Rechtslage ergeben. Auch wo entsprechende Differenzierungen nicht ausdrücklich im einfachen Recht angelegt sind, sind den Eingriffsmöglichkeiten von Verfassungs wegen engere Grenzen gesetzt in Abhängigkeit vom Grad der Bestimmtheit der Eingriffsnorm. So wurde die besonders weitreichende, die Eingriffsmöglichkeiten im Untersuchungshaftvollzug ganz allgemein regelnde Generalklausel des $§ 119$ Abs. 3 StPO a.F. zwar als ausreichende Rechtsgrundlage für Eingriffe in die Grundrechte des Untersuchungsgefangenen angesehen (s.u. D.I.2.), zugleich aber angenommen, dass sie engere Eingriffsmöglichkeiten eröffnet als vergleichbare, in ihrem Anwendungsbereich aber begrenztere Eingriffsnormen des Strafvollzugsrechts.

- „Die Auferlegung einer Beschränkung ist bei einer den Grundrechten Rechnung tragenden Auslegung des $\S 119$ Abs. 3 StPO nicht schon dann zulässig, wenn ein möglicher Mißbrauch eines Freiheitsrechts nicht völlig auszuschließen ist. Vielmehr müssen konkrete Anhaltspunkte dafür vorliegen, daß der Untersuchungsgefangene einen ihm überlassenen Gegenstand mißbrauchen und dadurch den Haftzweck oder die Ordnung in der Anstalt gefährden könnte (BVerfGE 35, 5 $<10>$; st. Rspr.).

Damit sind den durch $\S 119$ Abs. 3 StPO eröffneten Möglichkeiten des Eingriffs in das Grundrecht auf allgemeine Handlungsfreiheit (Art. 2 Abs. 1 GG) auch bei voller Ausschöpfung der Generalklausel vergleichsweise enge Grenzen gesetzt. Insbesondere deckt diese Vorschrift nicht einen Eingriff, der der Abwehr einer lediglich abstrakt-ge- 
nerellen Gefahr dient. Hierin besteht ein Unterschied zum Strafvollzug. Der jenen Bereich regelnde $\S 70$ StVollzG ist von Verfassungs wegen der Auslegung zugänglich, daß schon die einem Gegenstand allgemein innewohnende Gefährlichkeit ein Recht auf dessen Besitz ausschließt, ohne daß konkrete Anhaltspunkte für eine reale Gefährdung von Sicherheit oder Ordnung der Anstalt vorliegen müßten (vgl. Beschluß der 2. Kammer des Zweiten Senats des Bundesverfassungsgerichts vom 28. Februar 1994 - 2 BvR 2731/93 -, Umdruck S. 5). Dagegen kann der wenig bestimmten, zu Eingriffen unterschiedlichster Art berechtigenden Vorschrift des $\S 119$ Abs. 3 StPO wegen der damit verbundenen Relativierung der Grundrechte des Untersuchungsgefangenen ein solch umfassender Inhalt nicht beigemessen werden. “354

\section{Gesetzliche Eingriffsgrundlage}

a) Auslegung der strafprozessrechtlichen Eingriffsgrundlagen

Grundrechtseingriffe bedürfen, wie überall, so auch im Vollzug der Untersuchungshaft einer gesetzlichen Grundlage (s. zuletzt BVerfG II/2, Beschluss vom 30.10.2014 - 2 BvR 1513/14 -, juris; w.N. im Abschnitt zum Vorbehalt des Gesetzes, A.II.)

Die Generalklausel des $§ 119$ Abs. 3 StPO a.F., nach der Untersuchungsgefangenen (nur) solche Beschränkungen auferlegt werden durften, „die der Zweck der Untersuchungshaft oder die Ordnung in der Vollzugsanstalt erfordert", wurde als ausreichende Grundlage für Grundrechtseingriffe im Vollzug der Untersuchungshaft angesehen (BVerfGE 34, 369 $<379>$; 34, $384<395>$; 35, $307<309>$; 57, $170<177>$, stRspr; zur Vorgängerbestimmung auch bereits BVerfGE 15, $288<293 \mathrm{ff}$. >; aus der Kammerrechtsprechung s. nur BVerfG II/2, Beschluss vom 24.6.1996 - 2 BvR $2137 / 95$-, juris). Als ausreichende Eingriffsgrundlage galt die Vorschrift allerdings nur im Hinblick darauf, dass ihre Anwendung in besonderem Maße dem Grundsatz der Verhältnismäßigkeit (dazu näher im Folgenden unter 3.) verpflichtet sein sollte, und dass sie im Sinne einer engen Begrenzung der Eingriffsmöglichkeiten (BVerfG II/2, Beschluss vom

354 BVerfG II/2, Beschluss vom 25.7.1994 - 2 BvR 806/94 -, juris; zur Reichweite der Eingriffsermächtigung des $\S 119$ Abs. 3 StPO im Hinblick auf den Generalklauselartigen Charakter der Ermächtigung s. auch im Folgenden unter 2. 
19.7.1995 - 2 BvR 1439/95 -, juris; BVerfGK 17, $9<15>$, m.w.N) auszulegen war, nämlich dahingehend, dass sie Eingriffe nur bei konkreten Anhaltspunkten für eine reale Gefährdung der genannten eingriffsrechtfertigenden Belange erlaubte (BVerfGK BVerfGK 12, $378<380>$; 13, 163 $<164$ f. $>$, jew. m.w.N.), wobei es auf die Umstände des Einzelfalles ankam (BVerfG II/2, Beschluss vom 25.7.1995 - 2 BvR 806/94 -, juris; BVerfGK 12, $378<380>$; BVerfGK 20, $93<101>$, m.w.N.).

Die gegenwärtig geltende bundesgesetzliche Regelung des $\S 119$ Abs. 1 StPO beschränkt sich, gemäß dem im Jahr 2006 erfolgten Übergang der Gesetzgebungskompetenz für den Untersuchungshaftvollzug auf die Länder, auf die Regelung von Maßnahmen, die dem Zweck der Untersuchungshaft zu dienen bestimmt sind, und stellt für diesen Bereich eine ausreichende Rechtsgrundlage dar (BVerfG II/2, Beschluss vom 30.10.2014 - 2 BvR 1513/14 -, juris). In gleicher Weise und aus denselben Gründen wie die Vorgängerregelung des $\S 119$ Abs. 3 StPO a.F. ist allerdings auch § 119 Abs. 1 StPO einschränkend auszulegen.

- „Die Auslegung der Vorschriften des Untersuchungshaftrechts hat allerdings dem Umstand Rechnung zu tragen, dass ein Untersuchungsgefangener noch nicht rechtskräftig verurteilt ist und deshalb allein den unvermeidlichen Beschränkungen unterworfen werden darf (vgl. BVerfGE 15, $288<295>$; 34, $369<379>$; 42, $95<100>$; BVerfGK 13, $163<165>$ ). Der Grundsatz der Verhältnismäßigkeit muss daher den Vollzug der Untersuchungshaft in besonderem Maße prägen (vgl. BVerfGE 34, $369<380>$; 35, $5<9>$; 35, $307<309>$; BVerfGK a.a.O.). Die besonderen Anforderungen, die sich aus dem Grundsatz der Verhältnismäßigkeit für den Vollzug der Untersuchungshaft ergeben, begrenzen auch die Möglichkeit der Verallgemeinerung von Beschränkungen. Bei der Anwendung generalklauselartiger Vorschriften ist grundsätzlich die Berücksichtigung der Umstände des Einzelfalles geboten (vgl. BVerfGE 15, $288<297>$; 35, $5<11>$; 35, $307<309>$; BVerfGK 12, $378<380>$; 13, $163<165>$ ). Voraussetzung für die $\mathrm{Zu}-$ lässigkeit von Grundrechtseingriffen auf der Grundlage von § 119 StPO ist eine reale Gefährdung der in der Bestimmung bezeichneten öffentlichen Interessen (vgl. BVerfGE 15, $288<295>$; 34, $369<380>$ ), der durch die Inhaftierung allein nicht ausreichend entgegengewirkt werden kann. Für das Vorliegen einer solchen Gefahr müssen konkrete Anhaltspunkte bestehen (vgl. BVerfGE 35, $5<10>$; 42, $234<236>$; 57, $170<177>$ ). Die bloße Möglichkeit, dass ein Untersuchungsgefange- 
ner seine Freiheiten missbraucht, reicht nicht aus (vgl. BVerfGE 35, 5 $<10>$; BVerfG, Beschlüsse der 2. Kammer des Zweiten Senats vom 25. Juli 1994 - 2 BvR 806/94 -, NJW 1995, S. $1478<1480>$, vom 20. Juni 1996 - 2 BvR 634/96 -, juris, Rn. 8, und vom 10. Januar 2008 - 2 BvR 1229/07 - juris, Rn. 17).

Diese noch für die alte Gesetzesfassung aufgestellten Grundsätze gelten nach der Neufassung des $\S 119$ StPO gleichermaßen für die Anordnung von Beschränkungen nach Absatz 1 der Vorschrift (...).“355

Der bloße Verweis auf das Vorliegen der Haftgründe genügt zur Begründung von Maßnahmen nach $\S 119$ Abs. 1 StPO nicht.

- „Das Vorliegen der Haftgründe allein kann Anordnungen nach § 119 Abs. 1 StPO schon deshalb nicht rechtfertigen, weil diese bereits Voraussetzung der Untersuchungshaft und deshalb für sich genommen nicht geeignet sind, die Erforderlichkeit darüber hinausgehender Beschränkungen zu begründen." 356

Dass es grundsätzlich auf das Vorliegen der Eingriffsvoraussetzungen im konkreten Einzelfall ankommt, schließt generelle Anordnungen nicht aus, begrenzt aber deren Zulässigkeit und fordert die Einräumung von Ausnahmen, soweit ohne Gefährdung des Untersuchungshaftzwecks und der Anstaltsordnung möglich.

- „Dabei kommt es grundsätzlich auf den konkreten Einzelfall an (vgl. BVerfGE 15, $288<297>$; 35, $5<11>$ ); alle Umstände des Einzelfalls sind abzuwägen (vgl. BVerfGE $35,5<11>$ ). Dies schließt generelle Anordnungen - auch solche, die im Prinzip für alle Untersuchungsgefangenen gelten - nicht aus. Eine über Einzelmaßnahmen im konkreten Fall hinausgehende generelle Beschränkung ist aber nur dann zulässig, wenn eine reale Gefährdung der in $\S 119$ Abs. 3 StPO bezeichneten öffentlichen Interessen nicht jeweils durch einzelne Maßnahmen hinreichend abgewehrt werden kann (vgl.BVerfGE 34, $369<380>$; 34, 384 $<399$ f.>). In solchen Fällen ist zudem dem Grundsatz der Verhältnismäßigkeit dadurch Rechnung zu tragen, dass im Einzelfall Ausnahmen zugelassen werden, soweit dies ohne konkrete Gefährdung der in $§ 119$ Abs. 3 StPO genannten Interessen möglich ist (vgl. BVerfGE 15, 288 
$<294$ f. $>$; $34,384<398,400>$; 34, $384<398>$; 42, $95<102>$ ). Je weniger konkret die Gefährdung der Ordnung in der Anstalt ist, desto gröBeres Gewicht kommt der Handlungsfreiheit des Untersuchungsgefangenen zu und desto zurückhaltender muss der Richter bei grundrechtlichen Eingriffen sein (vgl. BVerfGE 57, // $170<177>$; BVerfG, Beschluss der 2. Kammer des Zweiten Senats vom 24. Juni 1996 - 2 BvR 2137/95 -, NStZ 1996, S. $509<510>$ ). “357

Der Begriff der „Ordnung in der Vollzugsanstalt“ (eingriffsrechtfertigender Belang nach $\S 119$ Abs. 3 StPO) ist nicht eng - in dem Sinne, dass es nur auf ein Mindestmaß an Ordnung ankäme - auszulegen. Um Belange der Ordnung der Anstalt handelt es sich jedoch nicht nur beim Schutz der Gefangenen vor unnötigen zusätzlichen Belastungen durch Lärm und Unruhe und vor Beeinträchtigungen ihrer Grundrechte aus Art. 2 Abs. 1 und 2 GG und beim Schutz der Sicherheit des Anstaltspersonals, sondern auch beim Funktionieren der Abläufe in der Anstalt, das durch Disziplinwidrigkeiten oder durch die Erzeugung von Spannungen zwischen Gefangenen und Personal gestört werden kann.

- „Es besteht kein Grund, den Rechtsbegriff "Ordnung in der Vollzugsanstalt" eng auszulegen und darunter nur ein Mindestmaß an Ordnung zu verstehen. Nicht nur die Rücksicht darauf, daß alle Untersuchungsgefangenen nicht unnötig zusätzlichen Belastungen durch Lärm, Unruhe usw. ausgesetzt und in gleicher Weise in ihrem Grundrecht aus Art. 2 Abs. 1 und Abs. 2 GG ungestört bleiben und nicht nur die Rücksicht auf die Sicherheit des Anstaltspersonals, sondern auch die Rücksicht darauf, daß das Funktionieren des Ablaufs des Lebens in der Anstalt nicht in Frage gestellt wird, sei es durch Disziplinwidrigkeiten der Insassen, sei es durch Erzeugung von Spannungen zwischen den Untersuchungsgefangenen und dem Aufsichtspersonal, sind Erwägungen, die die Ordnung in der Anstalt betreffen. “358

Bei konkreten Anhaltspunkten dafür, dass die Begehung einer Straftat bevorsteht, kann grundsätzlich ohne Verfassungsverstoß von einer Gefahr für die Ordnung der Anstalt ausgegangen werden.

357 BVerfGK 13, 163 (165 f.); ebenso BVerfGK 17, 9 (15).

358 BVerfGE 35, 311 (317). 
\,Den Fachgerichten ist es ... nicht verwehrt, eine Gefahr für die Ordnung in der Anstalt anzunehmen, wenn konkrete Anhaltspunkte dafür vorliegen, daß ein Untersuchungsgefangener dort eine Straftat begehen werde." 359

$\S 119$ Abs. 1 StPO kann, ebenso wie schon $\S 119$ Abs. 3 StOP a.F., ohne Verfassungsversto $\beta$ auch bei Überhaft als Eingriffsgrundlage genutzt werden (BVerfG II/2, Beschluss vom 30.10.2014 - 2 BvR 1513/14 -, juris, m.w.N.).

b) Bedeutung der Untersuchungshaftvollzugsordnung

Die Untersuchungshaftvollzugsordnung als an die Leitungen der Haftanstalten gerichtete allgemeine Verwaltungsvorschrift bindet den Richter nicht (BVerfGE 15, $288<294>$; 34, $369<379>$; BVerfGK 9, $365<370>$ ).

\section{Verhältnismäßigkeit}

$\mathrm{Zu}$ besonderen aus dem generalklauselartigen Charakter des $\S 119$ Abs. 3 StPO a.F. folgenden Verhältnismäßigkeitsanforderungen s. bereits o. D.I. 2.a).

Bloße Üblichkeit ist nicht geeignet, eine Beschränkung als verhältnismäßig zu rechtfertigen (BVerfGK 13, $163<166>$, m.w.N.).

Da viele von den Einschränkungen, denen Gefangene unterliegen, mit höherem Ressourceneinsatz vermeidbar wären, lässt sich die Verhältnismäßigkeit vieler Grundrechtseingriffe nicht ohne Berücksichtigung der Zumutbarkeit des Ressourceneinsatzes berurteilen, der zur Eingriffsvermeidung erforderlich wäre (allg. dazu s.o. A.VI.). Bei Untersuchungsgefangenen ist für die auch insoweit (allg. s. bereits o. D.I.1.) notwendige Abwägung zu berücksichtigen, dass sie noch nicht rechtskräftig verurteilt sind.

359 BVerfG II/2, Beschluss vom 24.6.1996 - 2 BvR 2137/95 -, juris; s. auch BVerfG II/2, Beschluss vom 3.12.2007 - 2 BvR 1686/07 -, juris, Auszug u. im Abschnitt zur Überwachung von Besuchen, D.IV.3., zur Gefahr von Straftaten zulasten der Gläubiger des Inhaftierten. Zur bei Beleidigungen bestehenden Ausnahme, wenn die Kommunikation in engen Vertrauensbeziehungen betroffen ist, s. noch u. im entsprechenden Abschnitt u. D.VI.1.b). 
„Auch Untersuchungsgefangene können zwar nicht verlangen, dass unbegrenzt personelle und sonstige Mittel aufgewendet werden, um zu vermeiden, dass wegen anderenfalls drohender Gefährdung des Zwecks der Untersuchungshaft eine Beschränkung ihrer grundrechtlichen Freiheiten erforderlich wird (vgl. BVerfGE 34, $369<380$ f. >; 34, $384<402>$; 42, $95<100$ f.>; BVerfGK, a.a.O.). Andererseits können aber nicht beliebige Einschränkungen allein damit gerechtfertigt werden, dass die gegebene personelle oder sonstige Ausstattung der Justizvollzugsanstalt nichts anderes zulasse; denn Grundrechte gelten nicht nach Maßgabe dessen, was an Verwaltungseinrichtungen im konkreten Fall oder üblicherweise vorhanden ist // (vgl. BVerfGE 15, $288<296>$; 34, $369<380$ f. $>$; 35, $307<310>$; BVerfGK 13, $163<166>$, m.w.N.). Es ist Sache des Staates, im Rahmen des Zumutbaren alle Maßnahmen zu treffen, die geeignet und nötig sind, um Verkürzungen der Rechte von Untersuchungsgefangenen zu vermeiden; die dafür erforderlichen sächlichen und personellen Mittel hat er aufzubringen, bereitzustellen und einzusetzen (vgl. BVerfGE 36, $264<275>$; 42, $95<101 \mathrm{f}$. $>$; BVerfGK, a.a.O., m.w.N.). Bei der abwägenden Bestimmung dessen, was einerseits dem Gefangenen an Beschränkungen, andererseits der Anstalt und dem für ihre angemessene Ausstattung verantwortlichen Staat an Aufwand zumutbar ist, muss der Umstand berücksichtigt werden, dass der Untersuchungsgefangene nicht rechtskräftig verurteilt ist (vgl. BVerfGE 15, $288<295>$; 34, $369<379>$; 42, $95<100>$ ), für die Zumutbarkeit der Haftbedingungen also der Gesichtspunkt keine Rolle spielen kann, dass der Betroffene sich durch strafbares Verhalten selbst unter diese Bedingungen versetzt habe (vgl. BVerfGK, a.a.O.). “360

Untersuchungsgefangene dürfen daher nur den unvermeidlichen Beschränkungen unterworfen werden.

- „Die Auslegung der Vorschriften des Untersuchungshaftrechts hat dem Umstand Rechnung zu tragen, dass ein Untersuchungsgefangener noch nicht rechtskräftig verurteilt ist und deshalb allein den unvermeidlichen Beschränkungen unterworfen werden darf (vgl. BVerfGE 15, 288 $<295>$; 34, $369<379>$; 42, $95<100>$; BVerfGK 13, $163<165>$ ).“"361

360 BVerfGK 20, 93 (100 f.), betr. die Länge und Verteilung der Ein- und Aufschlusszeiten; dazu weiter unten.

361 BVerfGK 20, 93 (100). 
Soweit es um den Aufwand geht, der zur Ermöglichung von Besuchskontakten getrieben werden muss, ist die besondere Bedeutung des Art. 6 Abs. 1 GG für den Haftvollzug zu berücksichtigen.

- „Zwar ist unvermeidliche Folge der Untersuchungshaft, daß der Untersuchungsgefangene Besuch von außerhalb der Anstalt lebenden Personen nur in begrenztem Umfang erhalten kann. Bei Gewährung von Besuchszeiten ist jedoch zu beachten, daß Ehe und Familie unter dem besonderen Schutz der staatlichen Ordnung stehen und der in Art. 6 I GG enthaltenen wertentscheidenden Norm im Haftvollzug besondere Bedeutung zukommt. Jede Untersuchungshaft von längerer Dauer stellt für die Beziehungen des Betroffenen zu seiner Familie regelmäßig eine empfindliche Belastung dar. Ihr Vollzug beeinträchtigt die notwendige Kommunikation zwischen dem Inhaftierten und seinen in Freiheit lebenden Angehörigen und kann dazu beitragen, daß sie einander tiefgreifend entfremdet werden. Aufgabe des Staates ist es, in Erfüllung seiner verfassungsrechtlichen Pflicht, für die Erhaltung von Ehe und Familie zu sorgen, solche nachteiligen Auswirkungen des Freiheitsentzugs im Rahmen des Möglichen und Zumutbaren, aber auch unter angemessener Beachtung der Belange der Allgemeinheit, zu begrenzen. Daraus folgt, daß die zuständigen Behörden die erforderlichen und zumutbaren Anstrengungen unternehmen müssen, um im angemessenen Umfang Besuche von Ehegatten von Untersuchungsgefangenen zu ermöglichen (vgl. BVerfGE 42, 95 (100, 101f.) = NJW 1976, 1311)، “362

Für die Verhältnismäßigkeit von Beschränkungen spielt auch eine Rolle, wie lange die Untersuchungshaft bereits andauert. So ist bei der Einräumung von Besuchszeiten für Angehörige zu berücksichtigen, ob die familiären Beziehungen bereits besonderen Belastungen duch die Dauer der Untersuchungshaft ausgesetzt sind (BVerfGE 42, $95<102>$ ). Bei der Beurteilung von Beschränkungen der Vertraulichkeit brieflicher Kommunikation ist es zu berücksichtigen, wenn die Dauer der Untersuchungshaft und/oder andere Anhaltspunkte dafür sprechen, dass der Gefangene sich in einer Krisensituation befindet (BVerfG II/2, Beschluss vom 19.7.1990 - 2 BvR 133/90 -, juris). Für den konkreten Fall offenlassend,

362 BVerfG II/2, Beschluss vom 25.7.1994 - 2 BvR 806/94 -, juris; dazu, dass eine Unterschreitung des von Art. 6 Abs. 1 GG geforderte Maßes an Besuchsmöglichkeiten nicht mit unzureichender Ausstattung der Vollzugsanstalt gerechtfertigt werden kann, s. auch BVerfGE 9, 371 (370 f.). 
ob die mit der Dauer der Untersuchungshaft zunehmende Belastung des Gefangenen durch Sicherungsvorkehrungen die derzeit noch hinzunehmenden Einschränkungen zu einem späteren Zeitpunkt unzumutbar machen könnte: BVerfG II/2, Beschluss vom 19.10.1993 - 2 BvR 1778/93 -, juris.

Grundsätzlich sind alle Umstände des Einzelfalles abzuwägen (BVerfGE 35, $5<11>$; BVerfGK 13, $163<165$ f. $>$, dort auch zu den Voraussetzungen der Zulässigkeit allgemeiner Anordnungen, s. Auszug o. D.I.2.a)).

4. Unschuldsvermutung und Gefahrenprognose

Die zugunsten der Gefangenen geltende Unschuldsvermutung (s. bereits o. 1.) hindert nicht die Berücksichtigung des bestehenden Straftatverdachts bei der Entscheidung über beschränkende Anordnungen.

- „Die zugunsten des Untersuchungsgefangenen geltende Unschuldsvermutung steht allerdings einer Berücksichtigung des dringenden Verdachts, bestimmte Straftaten begangen zu haben, im Rahmen der Beurteilung der Gefährlichkeit nicht entgegen. “363

„Die Unschuldsvermutung besagt, daß bis zum gesetzlichen Nachweis der Schuld eines wegen einer strafbaren Handlung Angeklagten dessen Unschuld vermutet wird (Art. 6 Abs. 2 der Europäischen Menschenrechtskonvention). Sie bezieht sich also ausschließlich auf die dem Beschuldigten zur Last gelegte Tat und schließt aus, gegen ihn im Vorgriff auf die Strafe Maßregeln zu verhängen, die in ihrer Wirkung der Freiheitsstrafe gleichkommen (BVerfGE 19, 342 (347)). Dagegen läßt sie Maßnahmen, die zur Aufrechterhaltung der Ordnung in der Vollzugsanstalt erforderlich sind, unberührt." ${ }^{\text {"364 }}$

Das bedeutet allerdings nicht, dass von dem bestehenden Verdacht bestimmter Straftaten ohne Weiteres Schlüsse auf die Gefährdung von Belangen gezogen werden könnten, die beschränkende Maßnahmen rechtfertigen.

364 BVerfGE 35, 311 (320); s. auch BVerfGE 35, 307 (310); 82, 106 (115). 
\,Das Oberlandesgericht hat das grundrechtliche Gebot der Abwägung im Einzelfall verkannt, indem es sich mit der Feststellung begnügte, die Möglichkeit eines Mißbrauchs sei angesichts der dem Beschwerdeführer zur Last gelegten Taten und seiner Verurteilung in erster Instanz nicht auszuschließen. Die Tatsache, daß ein Untersuchungsgefangener des Raubes und räuberischer Erpressung verdächtig und deshalb in erster Instanz zu einer Freiheitsstrafe von 5 Jahren verurteilt worden ist, läßt jedoch nicht ohne weiteres darauf schließen, daß er den Besitz einer Schreibmaschine zur Flucht mißbrauchen könnte. Entgegen dem von ihm selbst genannten Maßstab ist das Oberlandesgericht nicht von der individuellen Persönlichkeit des Beschwerdeführers, sondern offenbar von der allgemeinen Annahme ausgegangen, daß ein wegen solcher Straftaten zu hoher Freiheitsstrafe verurteilter Gefangener in jedem Falle zu Fluchtversuchen und zum Mißbrauch ihm über- // lassener Gegenstände zu diesem Zweck neigt, ohne auch nur diese allgemeine Annahme näher zu begründen. “365

\section{Richterliche Entscheidung}

Eine richterliche Anordnung von Beschränkungen in der Untersuchungshaft verletzt Grundrechte des betroffenen Untersuchungsgefangenen nicht bereits deshalb, weil zuvor ein anderer zuständiger Richter die Sicherungserfordernisse anders beurteilt hatte.

- „Die angegriffene Entscheidung begegnet nicht etwa deshalb verfassungsrechtlichen Bedenken, weil der Ermittlungsrichter beim Bundesgerichtshof im Rahmen seiner Zuständigkeit den Bezug von Zeitungen und Zeitschriften anders geregelt hatte.

Jeder nach $\S 126$ StPO zuständige Richter hat die für die Untersuchungshaft notwendigen Beschränkungen in eigener Verantwortung zu ordnen. Es ist möglich und verfassungsrechtlich nicht zu beanstanden, daß er bei dieser Entscheidung den Sicherungsbedürfnissen der Anstalt ein anderes Gewicht beimißt als der vor ihm zuständige Haftrichter.“366

365 BVerfGE 35, 5 (10 f.); zum zugrundeliegenden Gebot der Berücksichtigung der Umstände des Einzelfalles s.o. 3.

366 BVerfG, Beschluss vom 17.12.1981 - 2 BvR 1366/81 -, NStZ 1982, 132; in juris nur Orientierungssatz. 
Die Zuwiderhandlung eines Untersuchungsgefangenen gegen eine Anordnung des Haftrichters kann als Verletzung der Gehorsamspflicht nur geahndet werden, wenn die Anordnung dem Gefangenen bekanntgegeben wurde (BVerfGK 12, $378<382 \mathrm{f}$.>).

\section{Durchsuchung / Eingangsuntersuchung}

Zum erheblichen Gewicht des Eingriffs, der in einer mit Entkleidung verbundenen Durchsuchung liegt - erst recht, wenn sie mit einer Inspizierung von normalerweise bedeckten Körperöffnungen verbunden ist -, s. BVerfGK 17, 9 (14) sowie bereits oben im Abschnitt zu Durchsuchungen im Strafvollzug, B.XXV.

Das Einbringen von Drogen und anderen verbotenen Gegenständen stellt eine schwerwiegende Gefahr dar, zu deren Abwehr grundsätzlich auch derart schwerwiegende Eingriffe zulässig sind.

- „Zu Recht ist das Gericht allerdings davon ausgegangen, dass das Einbringen von Drogen und anderen verbotenen Gegenständen in Justizvollzugsanstalten eine schwerwiegende Gefahr für die Sicherheit und Ordnung der jeweiligen Anstalt darstellt, die grundsätzlich geeignet ist, grundrechtseingreifende // Maßnahmen - auch solche von erheblichem Gewicht - zur Abwehr dieser Gefahr auf der Grundlage des § 119 Abs. 3 StPO zu rechtfertigen (vgl. BVerfG, Beschluss der 2. Kammer des Zweiten Senats vom 6. November 2007 - 2 BvR 1136/07 -, NStZ 2008, S. $292<293>$ ).“367

Bei der Prüfung der Verhältnismäßigkeit eines solchen Eingriffs muss jedoch den besonderen Einschränkungen Rechnung getragen werden, die sich für die Zulässigkeit eingreifender Maßnahmen im Vollzug der Untersuchungshaft aus dem generalklauselartigen Charakter der Eingriffsermächtigung des $\S 119$ Abs. 3 StPO a.F. und aus den Besonderheiten der Untersuchungshaft ergeben (BVerfGK 17, $9<16>$; zu diesen besonderen Einschränkungen allg. bereits o. 1. und 2.). Grundsätzlich gerechtfertigte Durchsuchungsmaßnahmen, auch eine mit Entkleidung und Inspektion von normalerweise bedeckten Körperöffnungen verbundene Eingangsuntersuchung, sind - jedenfalls nach dem strengen Maßstab, nach dem die 
Verhältnismäßigkeit von Maßnahmen auf der Grundlage des § 119 Abs. 3 a.F. zu beurteilen ist - unverhältnismäßig, wenn besondere Umstände im Einzelfall dafür sprechen, dass die Gefahren, die den Eingriff grundsätzlich zu rechtfertigen geeignet sind, im konkreten Fall nicht vorliegen.

- „Hier verschafft schon der Umstand, dass Untersuchungshaft nicht auf der Grundlage rechtskräftiger Verurteilung, sondern auf der Grundlage bloßen Verdachts verhängt wird (vgl. BVerfGE 15, $288<295>$; 34, 369 $<379>$; BVerfG, Beschluss der 2. Kammer des Zweiten Senats vom 10. Januar 2008 - 2 BvR 1229/07 - www.bverfg.de), den Belangen des Gefangenen, die in die Prüfung der Verhältnismäßigkeit grundrechtseingreifender Maßnahmen einzustellen sind, besonderes Gewicht. Schon von daher verbietet sich eine schematische Übertragung von für den Strafvollzug geltenden Maßgaben. Der Verweis auf Nr. 76 UVollzO (zur fehlenden rechtlichen Außenwirkung vgl. BVerfGE 15, $288<294>$; 34, $369<379>$ ) in Verbindung mit $\S 84$ StVollzG ist deshalb nicht geeignet, eine ausnahmslose Anordnung von Durchsuchungen mit Inspektion von üblicherweise bedeckten Körperöffnungen bei Aufnahme in die Untersuchungshaft zu rechtfertigen.

... Bei Personen, die in Untersuchungshaft verbracht werden, können Umstände vorliegen, die den Verdacht, der oder die Betreffende könne zum Zweck des Einschmuggelns in die Haftanstalt Drogen oder andere gefährliche Gegen- // stände in Körperöffnungen des Intimbereichs versteckt haben, als derart fernliegend erscheinen lassen, dass hierauf gerichtete Untersuchungen, die mit einer Inspektion von Körperöffnungen verbunden sind, sich als nicht mehr verhältnismäßig erweisen. Anders als bei Verurteilten, die, wenn sie sich nicht bereits in Haft befinden, zum Haftantritt geladen werden ( $\$ 27$ StrVollstrO), kann die Festnahme eines nicht Verurteilten zur Verbringung in Untersuchungshaft so überraschend erfolgen, dass ihm für entsprechende unbeobachtete Vorkehrungen, selbst wenn er sie beabsichtigte, keine Gelegenheit bleibt. Fehlt es auch sonst an jedem Anhaltspunkt dafür, dass der Betroffene sich in der bezeichneten Weise zum Schmuggel von Drogen oder anderen gefährlichen Gegenständen präpariert haben könnte, so wird bereits die für Maßnahmen auf der Grundlage der Generalklausel des $\S 119$ Abs. 3 StPO erforderliche Schwelle einer - nur durch Inspektion der Körperhöhlen ausräumbaren - "realen" Gefährdung (vgl. BVerfGE 15, $288<295>$; 34, $384<398>$; 35, $5<9$ f. $>$; 35, $307<309>$ ) nicht erreicht. Auch wenn nach den Erfahrungen der Vollzugspraxis 
mit dem Versuch, Drogen oder andere verbotene Gegenstände in die Haftanstalten einzuschmuggeln, in weitem Umfang auch über den Kreis derer hinaus gerechnet werden muss, die drogenabhängig oder wegen einschlägiger Straftaten oder entsprechenden Verdachts inhaftiert sind, ist im Übrigen ein Eingriff, der auf die Abwehr dieser Gefahr zielt, jedenfalls dann unverhältnismäßig, wenn konkrete Umstände des Einzelfalles ein solches Vorkommnis aus dem Bereich der Wahrscheinlichkeit rücken (vgl. BVerfGE 15, $288<295>$ ). “368

$\mathrm{Zu}$ beanstanden ist es auch, wenn Möglichkeiten der milderen Ausgestaltung des Eingriffs wie die nach Auskunft der Justizbehörde üblicherweise praktizierte, das Schamgefühl weniger intensiv berührende Durchführung einer etwaigen Inspektion von Körperhöhlen durch einen Arzt oder eine Ärztin nicht erwogen werden (BVerfGK 17, 9<17>).

\section{Aufschlusszeiten}

Bei der Prüfung, ob eine Justizvollzugsanstalt bestehendes Ermessen hinsichtlich der Aufschlusszeiten für Untersuchungsgefangene fehlerfrei ausgeübt hat - wozu auch die Erkenntnis der Grenzen der Möglichkeit gehört, diesbezügliche Beschränkungen durch die Knappheit der personellen Ressourcen zu rechtfertigen (s. dazu bereits o. 3.) - ist zu berücksichtigen, dass ein Untersuchungsgefangener noch nicht rechtskräfig verurteilt ist (BVerfGK 20, $93<101$ f., 105 f.>; zu diesem Gesichtspunkt s. bereits o. 1.).

Die Ein- und Aufschlusszeiten müssen so beschaffen sein, dass die regulären Haftbedingungen sich von denen der Einzelhaft deutlich unterscheiden.

- „Es fehlt bereits an der notwendigen Auseinandersetzung mit der Frage, ob unter Haftbedingungen wie den vom Beschwerdeführer geschilderten der notwendige Abstand zu einer grundrechtswidrigen voraussetzungslosen Einzelhaft unterschritten ist.

Die unausgesetzte Absonderung eines Untersuchungsgefangenen (Einzelhaft) ist nach $\S 50 \mathrm{UVollzG} \mathrm{M}-\mathrm{V}$ nur aus in dessen Person liegenden Gründen unter engen Voraussetzungen zulässig. Arrest darf als beson- 
ders schwere, gemäß $§ 62$ Abs. 3 Satz 1 UVollzG M-V in Einzelhaft zu vollziehende Disziplinarmaßnahme, auch wenn von über den Einschluss in Einzelhaft hinausgehenden Beschränkungen gemäß $§ 62$ Abs. 2 Satz 3 UVollzG M-V abgesehen wird, nur für einen Zeitraum von höchstens vier Wochen ( $\$ 61$ Abs. 1 Nr. 7 UVollzG M-V) und nur wegen schwerer oder wiederholter Verfehlungen verhängt werden ( 61 Abs. 3 UVollzG M-V). Die engen gesetzlichen Voraussetzungen für die Anordnung dieser mit besonders weitreichendem Einschluss verbundenen Maßnahmen tragen dem Grundsatz der Verhältnismäßigkeit Rechnung, der hier besonders strikte Beachtung erfordert (vgl. für die Einzelhaft BVerfG, Beschluss der 2. Kammer des Zweiten Senats vom 13. April 1999 - 2 BvR 827/98 -, NStZ 1999, S. $428<429>$ ). Diesem Grundsatz läuft es jedenfalls zuwider, wenn bereits das normale Haftregime die Gefangenen Bedingungen unterwirft, die sich von denen der Einzelhaft kaum unterscheiden." ${ }^{\text {"369 }}$

Der notwendige Abstand zur Einzelhaft wird nicht schon dadurch gewahrt, dass die Möglichkeit der Kontaktaufnahme zu anderen Gefangenen während des täglichen einstündigen Hofgangs besteht.

- „In diesem Zusammenhang fällt es nicht ins Gewicht, wenn der ganztägige Einschluss durch den gesetzlich vorgesehenen - nicht primär der Kontaktpflege, sondern in erster Linie der körperlichen Gesunderhaltung dienenden - einstündigen Aufenthalt an der frischen Luft unterbrochen, also nicht zugleich auch noch von Nr. 27.1 der Europäischen Strafvollzugsgrundsätze und Nr. 42 Satz 2 der Empfehlung des Ministerkomitees des Europarates zur Untersuchungshaft abgewichen wird. Die Einräumung der täglichen Freistunde trägt zur Sicherung des hinsichtlich der Einschlusszeiten notwendigen Abstandes zur Vollzugssituation des Arrests oder der als besondere Sicherungsmaßnahmeangeordneten Einzelhaft nicht bei. Denn der insoweit nicht eingeschränkte Anspruch auf einstündigen Aufenthalt an der frischen Luft ( $\$ 20$ Abs. 2; $§ 62$ Abs. 3 Satz 3 // UVollzG M-V) bleibt dem Gefangenen wenn auch nicht als ein Anspruch, der die Möglichkeit sozialer Kontakte einschließt - in Übereinstimmung mit den genannten internationalen Standards auch im Vollzug von Arrest oder sonstiger Einzelhaft

369 BVerfGK 20, 93 (103). 
erhalten (vgl. zum Strafvollzugsrecht i.e.S. $\$ 89$ Abs. 2 Satz 2 StVollzG; ...)." ${ }^{370}$

Bestehen hinsichtlich der Ein- und Aufschlusszeiten erhebliche Unterschiede zwischen Straf- und Untersuchungsgefangenen sowie zwischen unterschiedlichen Gruppen von Untersuchungsgefangenen, so besteht auch Anlass, die Ermessensausübung unter dem Gesichtspunkt der Angemessenheit der Verteilung der Aufschlusszeiten im Verhältnis der verschiedenen Gruppen zu prüfen. Dabei sind Schlechterstellungen der Untersuchungsgefangenen nicht von vornherein ausgeschlossen; auch die Zuteilung personeller Ressourcen muss sich aber am Grundsatz der Verhältnismäßigkeit orientieren.

- „Insbesondere wären die erheblichen Unterschiede zwischen den für nicht arbeitende Untersuchungsgefangene und den für arbeitende Untersuchungsgefangene sowie Strafgefangene geltenden Aufschlusszeiten einer näheren Prüfung zu unterziehen gewesen. Das Landgericht hat sich der Sache nach mit den Ausführungen der Justizvollzugsanstalt dazu, dass die Personallage weitergehende Aufschlusszeiten für nicht arbeitende Untersuchungsgefangene nicht erlaube, zufriedengegeben, ohne der Frage nachzugehen, ob die Anstalt ihr Ermessen hinsichtlich der Verteilung der personellen Ressourcen im Verhältnis der genannten Gefangenengruppen fehlerfrei ausgeübt hat.

Eine vollzugliche Schlechterstellung von Untersuchungsgefangenen gegenüber Strafgefangenen ist in verschiedenen Bereichen wegen der besonderen Beschränkungen, die zur Sicherung des Zwecks der Untersuchungshafterforderlich sein können, nicht durchgängig vermeidbar. Aus der gebotenen Rücksicht darauf, dass der Untersuchungsgefangene nicht rechtskräftig verurteilt ist (...), und aus der gebotenen Rücksicht auf die besonderen mit der Untersuchungshaft verbundenen psychischen Belastungen (vgl. BVerfGK 13, $163<169$ f. $>$ ) folgt auch nicht, dass eine solche Schlechterstellung ohne weiteres immer bereits dann unzulässig ist, wenn sie durch Umschichtungen im Personaleinsatz vermeidbar wäre. Soweit etwa angesichts gegebener Unterschiede im Aufsichtsbedarf bereits geringfügige Verbesserungen bei den Untersuchungsgefangenen mit erheblichen Einschränkungen bei den Strafgefangenen erkauft werden müssten, ist es nicht zu beanstanden, wenn 
von einer Angleichung der Vollzugssituation durch Veränderungen in der Verteilung des Personaleinsatzes abgesehen wird. Andererseits entspräche es aber, auch soweit absolute Mindeststandards noch gewahrt sind, nicht der verfassungsrechtlich gebotenen Rücksicht auf die Besonderheit der Situation des Untersuchungsgefangenen, eine beliebige gegebene Verteilung personeller Ressourcen im Verhältnis zwischen den unterschiedlichen Gefangenengruppen zum feststehenden Ausgangspunkt der Prüfung zu nehmen und die Verhältnismäßigkeit der für Untersuchungsgefangene vorgesehenen Beschränkungen allein danach zu beurteilen, ob sie angesichts dieser gegebenen Ressourcenverteilung unvermeidbar sind. Vielmehr kann angesichts der Bedeutung, die ihr für das Ausmaß der hinzunehmenden Beschränkungen zukommt, auch die Verteilung der personellen Ressourcen selbst nicht der Prüfung daraufhin entzogen sein, ob ihr vertretbare, die besondere Situation der Untersuchungsgefangenen angemessen berücksichtigende sachliche Gründe zugrundeliegen. Eine solche Prüfung ist nicht erfolgt, obwohl angesichts der erheblichen Unterschiede zwischen den Aufschlusszeiten für die verschiedenen Gefangenengruppen und der erhebli- // chen Schlechterstellung gerade der nicht arbeitenden und insofern auf anderweitige Kontaktmöglichkeiten besonders angewiesenen Untersuchungsgefangenen die Möglichkeit einer Fehlgewichtung nicht fernlag.

Auch soweit allein die Situation unterschiedlicher Gruppen von Untersuchungsgefangenen und die gegebene Personalausstattung in diesem Bereich in den Blick genommen wird, fehlt jede weitere Aufklärung dazu, warum ein Aufschluss am Abend auf der Station trotz der erforderlichen Telefonkontrolle zwar für arbeitende Untersuchungsgefangene, nicht aber für nichtarbeitende Untersuchungsgefangene möglich sein soll, ob der tatsächliche Anfall von Überwachungsbedarf für Telefongespräche es erfordert, hierfür den gesamten dafür vorgesehenen Zeitraum von 17.00 bis 19.00 Uhr - auf Kosten von Möglichkeiten des Aufschlusses und des Umschlusses während dieser Zeit - vorzuhalten, und warum der nachmittägliche Aufschluss für nichtarbeitende Untersuchungsgefangene nur an drei Wochentagen stattfindet. Auch insoweit finden sich in dem Beschluss des Landgerichts keinerlei konkrete Ausführungen zu dem mit der Einräumung von Aufschlusszeiten und mit entgegenstehenden anderen Aufgaben verbundenen Zeit- und Personalaufwand, die eine Beurteilung der Erforderlichkeit der Einschlusszeiten erlauben würden. 
Dass das Landgericht nicht geprüft hat, ob die Einräumung erweiterter Aufschlusszeiten im Wege der individuellen Ausnahme für den Beschwerdeführer (vgl. BVerfGE 15, $288<294$ f. $>$; 34, $384<398$, 400>; 42, $95<102>$; BVerfGK 13, $163<165>$ ) erforderlich gewesen wäre, ist zwar im Hinblick darauf hinnehmbar, dass der Beschwerdeführer keinerlei für ihn persönlich sprechende Ausnahmegründe angeführt hatte. Das Landgericht hat jedoch, obwohl hierzu ein weiterführender Vortrag vom Beschwerdeführer nicht erwartet werden konnte, auch nicht überprüft, ob erweiterte Aufschlusszeiten, von denen auch der Beschwerdeführer profitieren könnte, im Wege der Differenzierung zugunsten von - etwa nach Haftgründen, Art der vorgeworfenen Delikte, Angewiesenheit auf zusätzliche Kontaktmöglichkeiten gebildeten - Untergruppen hätten zugelassen werden können und müssen." ${ }^{\text {371 }}$

IV. Besuch

\section{Allgemeines}

Beschränkungen des Besuchszugangs in der Untersuchungshaft greifen in das Grundrecht aus Art. 2 Abs. 1 GG ein (BVerfGE 34, $384<395>$; s. auch BVerfG II/2, Beschluss vom 30.10.2014 - 2 BvR 1513/14 -, juris; zur möglichen zusätzlichen Berührung von Rechten aus Art. 6 GG näher im Folgenden unter 2.; zur Berührung von Art. 2 Abs. 1 i.V.m. Art. 1 Abs. 1 GG bei Maßnahmen der akustischen Besuchsüberwachung unter 4.).

Dass Besuche in der Untersuchungshaft nur in begrenztem Umfang ermöglicht werden, gehört zu den in der Untersuchungshaft grundsätzlich hinzunehmenden Einschränkungen.

- „Untersuchungsgefangenen dürfen nach § 119 Abs 3 StPO nur solche Beschränkungen auferlegt werden, die der Zweck der Untersuchungshaft oder die Ordnung in der Vollzugsanstalt erfordert. Wie alle grundrechtseinschränkenden Bestimmungen ist auch diese Vorschrift an den durch sie eingeschränkten Grundrechten zu messen; ihre Auslegung

371 BVerfGK 20, 93 (105 f.), betr. einen Fall, in dem für nicht arbeitende Untersuchungsgefangene nur an drei Werktagen eineinhalbstündiger Aufschluss vorgesehen war, bei weitaus längeren Aufschlusszeiten für Strafgefangene. 
hat der Tatsache Rechnung zu tragen, daß ein Untersuchungsgefangener noch nicht verurteilt ist und deshalb allein den unvermeidlichen Beschränkungen unterworfen werden darf (vgl BVerfGE 15, 288 (295); 34, 384 (395f); 35, 5 (9f)), wobei die in § 119 Abs 3 StPO enthaltenen Generalklauseln voll ausgeschöpft werden dürfen (BVerfGE $35,311(316))$.

$\mathrm{Zu}$ diesen unvermeidlichen Beschränkungen gehören zwangsläufig auch alle diejenigen Begrenzungen der persönlichen Freiheit, die sich aus der Tatsache des Freiheitsentzuges und der Unterbringung in einer Vollzugsanstalt mit Notwendigkeit, gewissermaßen aus der "Natur der Sache" heraus, ergeben. Besuche eines Untersuchungsgefangenen durch außerhalb der Anstalt lebende Personen sind deshalb nur in begrenztem Umfang möglich, wobei sowohl die Untersuchungsgefangenen als auch die an einem Besuch interessierten Personen solche Einschränkungen als natürliche Folge des Freiheitsentzuges hinnehmen müssen. Im einzelnen sind darüber hinaus alle diejenigen Einschränkungen und Überwachungsmaßnahmen zulässig, die die Vermeidung von Fluchtgefahr oder Verdunk- // lungsgefahr erfordert.“372

Im Übrigen dürfen Besuchsbeschränkungen auf der Grundlage des § 119 Abs. 1 StPO allerdings nur unter den bei der Auslegung und Anwendung dieser Vorschrift allgemein zu beachtenden engen Voraussetzungen verhängt werden (BVerfG II/2, Beschluss vom 30.10.2014 - 2 BvR 1513/14 -, juris, Auszug oben unter D.I.2.a); Näheres im dortigen Abschnitt).

Generelle Beschränkungen des Besuchsverkehrs sind mit dem Grundsatz der Verhältnismäßigkeit vereinbar, wenn und soweit eine reale Gefährdung der in der Eingriffsnorm bezeichneten öffentlichen Interessen nicht jeweils durch Einzelmaßnahmen hinreichend abgewehrt werden kann. Der Grundsatz der Verhältnismäßigkeit gebietet jedoch, Ausnahmen von der generellen Beschränkung zu gestatten, wenn im konkreten Fall eine reale Gefährdung des Haftzweckes oder der Ordnung in der Anstalt ersichtlich nicht zu befürchten ist.

- „Die Beschränkung des Besuchsverkehrs der Beschwerdeführer B... und M... auf Angehörige, wie sie durch Ziff. 1 des Beschlusses des Ermittlungsrichters des Bundesgerichtshofes vom 12. Juni 1972 angeord-

372 BVerfGE 42, 95 (100 f.); s. auch BVerfG II/2, Beschluss vom 13.8.1993 - 2 BvR $1469 / 93$-, juris. 
net worden ist, verletzt nicht das Grundrecht dieser Beschwerdeführer aus Art. 2 Abs. 1 GG. Die Anordnung beeinträchtigt zwar die freie Entfaltung der Persönlichkeit der Beschwerdeführer nicht unerheblich; dem persönlichen Gespräch insbesondere mit Freunden und Bekannten kann gerade in der Untersuchungshaft erhöhte Bedeutung zukommen. Das Grundrecht des Art. 2 Abs. 1 GG ist jedoch von vornherein nur unter dem Vorbehalt der verfassungsmäßigen Ordnung gewährleistet. ... // ... Weder die Bedeutung des Grundrechts der freien Entfaltung der Persönlichkeit noch der Grundsatz der Verhältnismäßigkeit, von dem die Untersuchungshaft in Anordnung wie Vollzug beherrscht werden muß (BVerfGE 19, 342 [347]), schließen eine über eine einzelne Maßnahme hinausgehende generelle Beschränkung von vornherein aus. Generelle Maßnahmen sind allerdings nur zulässig, wenn eine reale Gefährdung der in $\S 119$ Abs. 3 StPO bezeichneten öffentlichen Interessen nicht jeweils durch Einzelmaßnahmen hinreichend abgewehrt werden kann." ${ }^{373}$

Das Ausmaß der zulässigen Beschränkungen hängt auch von der räumlichen und personellen Ausstattung der Vollzugsanstalt ab.

- „Bei alledem sind auch jeweils die räumliche und personelle Ausstattung der jeweiligen Justizvollzugsanstalt und die sich daraus ergebenden Grenzen für die Möglichkeit der Durchführung von Besuchen in Betracht zu ziehen. Die äußerste Grenze der Zulässigkeit einer Beschränkung von Besuchsmöglichkeiten ist erst dann überschritten und damit Verfassungsrecht verletzt, wenn die Verweigerung einer Besuchserlaubnis weder zur Sicherung der Haftzwecke noch der Anstaltsordnung geboten ist und in ihrer Belastung für die Betroffenen über das situationsbedingt typische Ausmaß erheblich hinausreicht. Das gilt vor allem dann, wenn hierdurch Elemente der verfassungsrechtlich festgelegten Wertordnung berührt werden. “374

Der Grundsatz der Verhältnismäßigkeit verpflichtet dazu, bei der Entscheidung über Anträge auf Besuchserlaubnis zu prüfen, ob die Fortdau-

373 BVerfGE 34, 384 (395 f.), zu § 119 Abs. 3 StPO a.F.; zur Übertragbarkeit der Rechtsprechung zu dieser Vorschrift auf die Anwendung des $\S 119$ Abs. 1 StPO s. allg. BVerfG II/2, Beschluss vom 30.10.2014 - 2 BvR 1513/14 -, juris.

374 BVerfGE 42, 95 (101); s. auch BVerfG II/2, Beschluss vom 13.8.1993 - 2 BvR $1469 / 93$-, juris. 
er einer angeordneten generellen Beschränkung (zur Möglichkeit genereller Beschränkungen s.o. D.I.2.a)) noch angemessen ist.

- „Der Grundsatz der Verhältnismäßigkeit gebietet außerdem, daß der Ermittlungsrichter bei der Ablehnung von Anträgen auf Erteilung einer Besuchserlaubnis von Amts wegen prüft, ob die tatsächlichen Verhältnisse, die der Anordnung der Besuchsbeschränkung zugrunde lagen, noch fortbestehen oder ob angesichts zwischenzeitlich eingetretener Veränderungen die generelle Beschränkung nicht mehr gerechtfertigt ist. “" 375

Zur Verfassungsmäßigkeit der auch den Postverkehr betreffenden Kontaktsperre nach $\S \S 31 \mathrm{ff}$. EGGVG in der damaligen Fassung s. BVerfGE 49, 24 (53 ff.); näher oben im den Strafvollzug i.e.S. betreffenden Abschnitt über Besuche, B.XIII.3.

\section{Familienangehörige}

Besondere Bedeutung für die Entscheidung über Besuchskontakte in der Untersuchungshaft kommt dem grundrechtlichen Schutz der Familenbeziehungen $\mathrm{zu}$ (s. auch bereits o. B.XIII.1.).

„Ehe und Familie stehen unter dem besonderen Schutz der staatlichen Ordnung (Art 6 Abs 1 GG). Daraus hat das Bundesverfassungsgericht eine Reihe von rechtlichen Folgerungen gezogen (BVerfGE 6, 55 (71ff); 6, 386 (388); 24, 119 (135); 28, 104 (112); 31, 58 (67)). Hier ist entscheidend, daß der in Art 6 Abs 1 GG enthaltenen wertentscheidenden Grundsatznorm auch im Haftvollzug besondere Bedeutung zukommt. Jede Untersuchungshaft von längerer Dauer stellt für die Beziehungen des Betroffenen zu seiner Familie regelmäßig eine empfindliche Belastung dar. Ihr Vollzug beeinträchtigt die notwendige Kommunikation zwischen dem Inhaftierten und seinen in Freiheit lebenden Angehörigen und kann dazu beitragen, daß sie einander tiefgreifend entfremdet werden. Aufgabe des Staates ist es, in Erfüllung seiner verfassungsrechtlichen Pflicht, für die Erhaltung von Ehe und Familie zu sorgen, solche nachteiligen Auswirkungen des Freiheitsentzuges im 
Rahmen des Möglichen und Zumutbaren, aber auch unter angemessener Beachtung der Belange der Allgemeinheit zu begrenzen." ${ }^{376}$

Für Besuche von Ehegatten und Kindern kann grundsätzlich auf die allgemeinen Besuchstage verwiesen werden; in Ausnahmefällen kann aber zur Schaffung zumutbarer Besuchsmöglichkeiten die Inkaufnahme besonderen organisatorischen und personellen Aufwandes - etwa durch die Ermöglichung von Besuchen am Wochenende - notwendig und geboten sein.

- „Daraus folgt, daß die zuständigen Behörden die erforderli- // chen und zumutbaren Anstrengungen unternehmen müssen, um in angemessenem Umfange Besuche von Ehegatten und Kindern von Untersuchungsgefangenen zu ermöglichen. Auch für sie stehen allerdings im Interesse eines geordneten Anstaltsbetriebes grundsätzlich nur die allgemeinen Besuchstage zur Verfügung. Nur in besonders gelagerten Ausnahmefällen kann es geboten und für die Justizvollzugsanstalt auch zumutbar sein, für besuchsberechtigte Ehegatten und Kinder von Untersuchungsgefangenen Besuchsgelegenheiten außerhalb der allgemeinen Besuchstage zu schaffen.

Ein solcher Ausnahmefall ist hier gegeben. Der Beschwerdeführer befindet sich seit etwa eineinhalb Jahren in Untersuchungshaft, so daß die Aufrechterhaltung seiner familiären Bindungen besonders gefährdet erscheint. Die generelle Ablehnung von Samstagbesuchen hat in der Vergangenheit dazu geführt, daß die Beschwerdeführerin wegen der weiten Entfernung zwischen dem Wohnort der Familie und der Haftanstalt sowie wegen ihrer Berufstätigkeit nur unter unverhältnismäßigen Schwierigkeiten und Opfern den Beschwerdeführer besuchen konnte.

Die organisatorischen und personellen Schwierigkeiten, welche für die Vollzugsanstalt mit Besuchen an Wochenenden verbunden sind, vermögen eine so schwerwiegende Belastung der familiären Beziehungen der Beschwerdeführer nicht zu rechtfertigen. Diese Schwierigkeiten sind jedenfalls nicht so unüberwindlich, daß ihnen gegenüber bei der vorzunehmenden Abwägung zwischen der wertentscheidenden Grund-

376 BVerfGE 42, 95 (101); s. auch BVerfG II/2, Beschluss vom 25.7.1994 - 2 BvR $806 / 94-$, juris. 
satznorm des Art 6 Abs 1 GG und den Belangen des Vollzuges der Verfassungsrechtssatz zurücktreten müßte.

In einem Ausnahmefall der hier vorliegenden Art müssen deshalb Besuchsmöglichkeiten auch zum Wochenende in ausreichendem und angemessenem Umfange geschaffen werden (vgl BVerfGE 36, 264 f.)." 377

Die Ausststattung der Justizvollzugsanstalten muss zudem ihrerseits so beschaffen sein, dass den grundrechtlichen Ansprüchen der Gefangenen Rechnung getragen werden kann. Unzureichende Besuchsmöglichkeiten werden nicht dadurch grundrechtskonform, dass sie auf unzureichender Ausstattung der Anstalt beruhen.

- „Diesem Vortrag ist zu entnehmen, daß die Justizvollzugsanstalt aus Gründen unzureichender - der Belegung der Anstalt nicht entsprechender - Personalausstattung die Zahl der allgemeinen Besuchstage beschränkt. Das durften die Fachgerichte nicht unberücksichtigt lassen. Wie das Bundesverfassungsgericht bereits entschieden hat, kann sich der Staat dem Untersuchungsgefangenen gegenüber nicht darauf berufen, daß er seine Gerichte nicht so ausstattet, wie es erforderlich ist, um die anstehenden Verfahren ohne vermeidbare Verzögerung abzuschließen. Es ist seine Aufgabe, im Rahmen des Zumutbaren alle Maßnahmen zu treffen, die geeignet und nötig sind, einer Überlastung der Gerichte vorzubeugen und ihr dort, wo sie eintritt, rechtzeitig abzuhelfen. Er hat die dafür erforderlichen - personellen wie sächlichen - Mittel aufzubringen, bereitzustellen und einzusetzen (vgl. BVerfGE 36, 264 $(275)=$ NJW 1974, 307). Nichts anderes gilt für Eingriffe, die sich aus einer Überlastung der Justizvollzugsanstalten ergeben (vgl. BVerfGE 42, 95 (102) = NJW 1976, 1311).“378

Das größere oder geringere Ausmaß an familiären Bindungen, die des Schutzes bedürfen, stellt einen zulässigen Grund für Differenzierungen bei der Einräumung von Besuchszeiten dar.

- „Sollte der Beschwerdeführer unter Berücksichtigung dieser Erwägungen in den Genuß einer großzügigeren Besuchsregelung kommen als andere Gefangene, die sich aufgrund eines Haftbefehls des gleichen

377 BVerfGE 42, 95 (101 f.).

378 BVerfG II/2, Beschluss vom 25.7.1994 - 2 BvR 806/94 -, juris. 
Gerichts in Untersuchungshaft befinden, so vermag dies eine Verletzung des allgemeinen Gleichheitssatzes (Art. 3 Abs. 1 GG) nicht zu begründen. Soweit andere Untersuchungsgefangene geringere familiäre Bindungen haben oder die Verhältnisse der jeweiligen Haftanstalt weitergehende Besuchsmöglichkeiten nicht zulassen, liegen sachliche Gründe vor, die eine Differenzierung erlauben. In den übrigen Fällen könnte die Gewährung gleichfalls umfangreicherer Besuchserlaubnisse angezeigt sein." ${ }^{379}$

Die Einräumung großzügigerer Besuchszeiten für Ehegatten als für Kinder kann nicht mit dem Hinweis auf den grundrechtlichen Schutz der Ehe gerechtfertigt werden.

- „Der Hinweis der Anstaltsleitung auf Art. 6 Abs. 1 GG rechtfertigt die Ungleichbehandlung nicht, weil diese Norm Ehe und Familie unter den Schutz der staatlichen Ordnung stellt. Für die Verteilung von Begünstigungen zwischen "Ehe" und "Familie" ist ihr daher kein Maßstab zu entnehmen (vgl. BVerfGE 11, $64<69>$ ).

Der Hinweis der Anstaltsleitung auf Art. 6 Abs. 1 GG rechtfertigt die Ungleichbehandlung nicht, weil diese Norm Ehe und Familie unter den Schutz der staatlichen Ordnung stellt. Für die Verteilung von Begünstigungen zwischen "Ehe" und "Familie" ist ihr daher kein Maßstab zu entnehmen (vgl. BVerfGE 11, $64<69>$ ). "380

Grundrechtlich geschützt ist auch der Kontakt des Kindes zu einem getrennt lebenden Elternteil.

- „Das Oberlandesgericht ist allerdings zutreffend davon ausgegangen, dass der persönliche Kontakt des Kindes zu einem getrennt lebenden Elternteil grundrechtlich geschützt ist, dass der damit verbundene Aufbau und die Kontinuität emotionaler Bindungen zu Vater und Mutter in aller Regel der Persönlichkeitsentwicklung des Kindes dient, und dass der spezifische Erziehungsbeitrag des Vaters nicht durch die Betreuung des Kindes seitens der Mutter entbehrlich wird (vgl. BVerfGE 56, 363

379 BVerfG II/2, Beschluss vom 13.8.1993 - 2 BvR 1469/93 -, juris, mit Erlass einer einstweiligen Anordnung nach $\S 32$ BVerfGG dahingehend, dass dem Beschwerdeführer, wie nach Auskunft der Anstalt ohne Gefährdung der Anstaltsordnung möglich, wöchentlich ein insgesamt halbstündiger Besuch von seiner Ehefrau und seinem Sohn zu gestatten sei.

380 BVerfGK 9, 365 (370). 
$<384>$; 79, $51<63$ f. $>$; Beschluss der 1. Kammer des Zweiten Senats des Bundesverfassungsgerichts vom 20. März 1997 - 2 BvR 260/97 -, juris; Beschluss der 2. Kammer des Zweiten Senats des Bundesverfassungsgerichts vom 8. Dezember 2005 - 2 BvR 1001/04 -, FamRZ 2006, S. $187<188$ f.>)، “381

Das gilt auch für Kinder im Säuglingsalter; eine im Hinblick auf die einzuräumenden Besuchszeiten geringere Schutzbedürftigkeit der Kontakte von Kindern dieses Alters zu einem inhaftierten Elternteil ist aus der Rechtsprechung nicht abzuleiten.

- „Die aus der Rechtsprechung des Bundesverfassungsgerichts zutreffend wiedergegebene Feststellung, nach der die Entwicklung eines Kindes nicht nur durch quantifizierbare Betreuungsbeiträge der Eltern, sondern auch durch die geistige und emotionale Auseinandersetzung geprägt wird (vgl. Beschluss der 2. Kammer des Zweiten Senats des Bundesverfassungsgerichts vom 30. Januar 2002 - 2 BvR 231/00 -, FamRZ 2002, S. $601<603>$; Beschluss der 2. Kammer des Zweiten Senats des Bundesverfassungsgerichts vom 8. Dezember $2005-2$ BvR 1001/04 -, FamRZ 2006, S. $187<188>$ ), wäre grundlegend missverstanden, wenn sie in diesem Zusammenhang als eine Aussage gedeutet würde, die die Schutzwirkung des Art. 6 Abs. 1 und Abs. 2 GG in Bezug auf die Möglichkeit des Kontakts zwischen Eltern und Kindern relativiert, soweit es dabei um quantitative Fragen wie die Dauer der zuzugestehenden Besuchsmöglichkeiten geht. Ebensowenig folgt aus ihr, dass der grundrechtliche Schutz dieses Kontakts von geringerem Gewicht wäre, soweit er Kinder betrifft, mit denen eine geistige Auseinandersetzung noch nicht möglich ist." 382

\section{Andere Besucher}

Die richterliche Anordnung, dass ein Untersuchungsgefangener Besuch nur von Familienangehörigen empfangen darf, andere Besucher also ausgeschlossen sind, kann als Anordnung, von der in besonderen Fällen Ausnahmen zu machen sind, gerechtfertigt sein, wenn Anhaltspunkte für 
eine sonst drohende schwerwiegende Gefährdung der Haftzwecke bestehen.

- „Der Bundesgerichtshof hat hierzu in dem angefochtenen Beschluß ausgeführt: Bei den Beschwerdeführern bestehe Verdunkelungsgefahr und erhöhter Fluchtverdacht. Es sei bekannt, daß mutmaßliche Mitglieder der kriminellen Vereinigung, der anzugehören die Beschwerdeführer dringend verdächtig seien, die Befreiung "politischer Gefangener" propagiert und in einzelnen Fällen konkret geplant hätten. Daher sei zu befürchten, daß noch nicht festgenommene Mitglieder der kriminellen Vereinigung oder mit dieser Vereinigung sympathisierende Personen bei Besuchen in verschlüsselter Form Mitteilungen über Befreiungspläne oder über das Ermittlungsverfahren überbringen könnten, ohne daß die den Besuch überwachenden Beamten in der Lage wären, die Verschlüsselung zu erkennen und derartige Mitteilungen zu verhindern. Eine vorherige Überprüfung der Besucher // werde zudem dadurch außerordentlich erschwert oder sogar unmöglich gemacht, daß nach bisherigen Erfahrungen die Besuchserlaubnis zum Teil unter falschen Namen und Vorlage von gefälschten Ausweisen beantragt werde. Daher könne der aufgezeigten schwerwiegenden Gefährdung des Haftzweckes nur durch eine generelle Beschränkung des Besuchsverkehrs auf die Angehörigen begegnet werden.

Es ist nicht Aufgabe des Bundesverfassungsgerichts, die von den zuständigen Gerichten getroffenen tatsächlichen Feststellungen auf ihre Richtigkeit zu überprüfen (BVerfGE 4, 294 (297); 12, 1 (5); 20, 144 (149 f.)). Willkür oder einen Verstoß gegen spezifisches Verfassungsrecht lassen die Ausführungen des Bundesgerichtshofes nicht erkennen. ...

Mit dem Grundsatz der Verhältnismäßigkeit wäre die angegriffene Maßnahme allerdings nicht vereinbar, wenn sie der Erteilung einer Besuchserlaubnis an eine nicht zu den Angehörigen zählende Person auch für den Fall entgegenstünde, daß eine Gefährdung des Haftzweckes ersichtlich nicht zu befürchten ist. Eine solche Wirkung kommt dem Beschluß des Ermittlungsrichters jedoch nicht zu. ${ }^{\text {"383 }}$

383 BVerfGE 34, 384 (396 f.); s. im Folgenden S. 397 f. dazu, dass der Ermittlungsrichter nicht gehindert sei, im Einzelfall Ausnahmen von der angeordneten Beschränkung zu erlassen. 
Die auf $\S 119$ Abs. 3 StPO a.F. gestützte Versagung der Erlaubnis für den Besuch eines Journalisten zum Zweck der Führung eines Interviews greift in die Grundrechte des betroffenen Gefangenen aus Art. 2 Abs. 1 und Art. 5 Abs. 1 GG ein und verletzt diese Grundrechte, wenn es an konkreten Anhaltspunkten für eine reale Gefahr für die in $\S 119$ Abs. 3 StPO a.F. genannten eingriffsrechtfertigenden Belange fehlt (BVerfG II/2, Beschluss vom 19.7.1995 - 2 BvR 1439/95 -, juris; die Entscheidung ist zwar zu der damals für die Untersuchungshaft maßgeblichen Eingriffsnorm ergangen, betraf aber den Fall eines Gefangenen in Auslieferungshaft, so dass die Bedeutung der Möglichkeit von Interviewäußerungen für die Zwecke des Strafverfahrens nicht zu erörtern war).

\section{4. Überwachungs- und Kontrollmaßnahmen}

Maßnahmen der akustischen Besuchsüberwachung greifen in das Grundrecht sowohl des Gefangenen als auch des Besuchers aus Art. 2 Abs. 1 in Verbindung mit Art. 1 Abs. 1 ein (BVerfG II/2, Beschluss vom 20.6.1996 - 2 BvR 634/96 -, juris; s. auch, für den betroffenen Gefangenen, BVerfG II/2, Beschluss vom 30.10.2014 - 2 BvR 1513/14 -, juris, m.w.N.).

Art. 6 Abs. 1 GG fordert, dass Maßnahmen der Überwachung von Besuchskontakten mit Angehörigen auf das Unumgängliche beschränkt werden und ihre Notwendigkeit besonders eingehend geprüft wird. Bei anderen Personen kann Anlass bestehen, die besondere Enge der Beziehung im Rahmen der Prüfung der Verhältnismäßigkeit zu berücksichtigen.

- „Das Kammergericht hat die Besuche des Sohnes auch nicht mit Blick auf Art. 6 Abs. 1 GG gewürdigt. Diese Vorschrift stellt Ehe und Familie unter den besonderen Schutz der staatlichen Ordnung und wirkt als wertentscheidende Grundsatznorm auf die Gestaltung des Haftvollzugs ein. Daraus folgt zunächst, daß die zuständigen Behörden die erforderlichen und zumutbaren Anstrengungen unternehmen müssen, um in angemessenem Umfange Besuche von Ehegatten und Kindern von Untersuchungsgefangenen zu ermöglichen (BVerfGE 42, $95<101$ f. $>$ ). Dies bedeutet aber selbstverständlich nicht nur, daß der Besuch als solcher ermöglicht wird, sondern auch, daß Maßnahmen, die den Besuch belasten, auf das Unumgängliche beschränkt bleiben. Es bedarf daher bei Besuchen von Familienangehörigen einer besonders ernstlichen und 
eingehenden, auch die Dauer der erlittenen Untersuchungshaft einbeziehenden und am Kriterium der Zumutbarkeit orientierten Prüfung, ob eine Besuchsbeschränkung unverzichtbar vom Zweck der Untersuchungshaft oder der Ordnung in der Vollzugsanstalt gefordert wird. Diese ihm obliegende Prüfung hat das Kammergericht nicht ausreichend vorgenommen.

Es hat aber ebenso auch die Frage übergangen, ob das nicht dem Schutz des Art. 6 Abs. 1 GG unterstellte Verhältnis des Beschwerdeführers zu der als seine Lebensgefährtin bezeichneten Frau derart eng ist, daß es im Rahmen des durch Art. 2 Abs. 1 GG gewährleisteten Freiheitsrechts eine besondere Würdigung unter den Gesichtspunkten des Grundsatzes der Verhältnismäßigkeit (Art. 20 Abs. 3 GG) zugunsten des Beschwerdeführers verlangt.“"384

Akustische Besuchsüberwachung stellt einen erheblichen Eingriff in die Grundrechte der Betroffenen aus Art. 2 Abs. 1 i.V.m. Art. 1 Abs. 1 GG dar, der nur bei Vorliegen konkreter Anhaltspunkte für eine Gefährdung der eingriffsrechtfertigenden Belange zulässig ist.

- „Die 2. Kammer des Zweiten Senats des Bundesverfassungsgerichts hat sich bereits mit Beschluß vom 31. August 1993 - 2 BvR 1479/93 (vgl. NStZ 1994, S. 52) mit der akustischen Besuchsüberwachung während der Untersuchungshaft befaßt. Diese stellt einen erheblichen Eingriff in den persönlichen, durch Art. 2 Abs. 1 GG i.V.m. Art. 1 Abs. 1 GG geschützten Lebensbereich sowohl des Gefangenen als auch des Besuchers dar. Der Richter hat daher - wie bei allen grundrechtseinschränkenden Anordnungen gemäß $§ 119$ Abs. 3 StPO - stets zu prüfen, ob im Einzelfall konkrete Anhaltspunkte für einen Mißbrauch, der eine Gefährdung von Haftzweck oder Ordnung der Anstalt mit sich brächte, vorliegen (vgl. BVerfG, a.a.O.). Der Umstand allein, daß ein möglicher Mißbrauch eines Freiheitsrechts nicht völlig auszuschließen ist, reicht bei einer den Grundrechten Rechnung tragenden Auslegung des $\S 119$ Abs. 3 StPO nicht aus, um Beschränkungen anzuordnen (vgl. BVerfGE 35, $5<10>$ ). Stellt die einschränkende Maßnahme auch einen Eingriff in das Grundrecht aus Art. 6 Abs. 1 GG dar, bedarf es einer besonders ernstlichen und eingehenden, auch die Dauer der Untersu-

384 BVerfG II/2, Beschluss vom 31.8.1993 - 2 BvR 1479/93 -, juris, betr. die akustische Überwachung von Besuchen des Sohnes und der Lebensgefährtin des Beschwerdeführers. 
chungshaft einbeziehenden und am Kriterium der Zumutbarkeit orientierten Prüfung, ob eine Besuchseinschränkung unverzichtbar vom Zweck der Untersuchungshaft oder der Ordnung im Vollzug gefordert wird (vgl. BVerfG, NStZ 1994, S. 52).

Diesen Anforderungen wird der angegriffene Beschluß des Landgerichts Düsseldorf nicht gerecht. Es hat seiner Entscheidung ausdrücklich die unzutreffende Auffassung zugrunde gelegt, konkreter Anhaltspunkte für eine Mißbrauchsgefahr bedürfe es nicht, es reiche schon aus, daß Anweisungen, die "ggf. auf Verdunkelungsgefahr hinauslaufen", nicht auszuschließen seien. Dem vom Landgericht nur spärlich angedeuteten Sachverhalt einer möglicherweise unerlaubten Briefübermittlung unter Einschaltung des Verteidigers sind keine konkreten Anhaltspunkte für eine Gefährdung des von $\S 19$ Abs. 3 StPO geschützten Zwecks der Haft - nach dem Haftbefehl allein der Ausschluß der Fluchtgefahr - zu entnehmen. Bereits deshalb kann die angegriffene Entscheidung, soweit sie die akustische Besuchsüberwachung beim Beschwerdeführer betrifft, keinen Bestand haben. Auf weiteres kommt es nicht an. ${ }^{\text {‘3 } 385}$

Bei Gefahr der Begehung von Straftaten ist die akustische Überwachung von Kontakten mit den Angehörigen zur Wahrung der Anstaltsordnung zulässig.

- „Die Voraussetzungen, unter denen eine Verfassungsbeschwerde zur Entscheidung anzunehmen ist (§93a Abs. 2 BVerfGG), liegen nicht vor. Die Verfassungsbeschwerde hat weder grundsätzliche Bedeutung ( $993 \mathrm{a}$ Abs. 2 Buchstabe a BVerfGG), noch ist ihre Annahme zur Durchsetzung von Grundrechten oder grundrechtsgleichen Rechten des Beschwerdeführers angezeigt ( $(93 a$ Abs. 2 Buchstabe b BVerfGG). Zwar ist die Entscheidung des Oberlandesgerichts in teilweise angreifbarer Weise begründet. Sie konnte aber im Ergebnis nicht anders ausfallen. Dem Beschwerdeführer entsteht daher durch die Nichtannahme kein schwerer Nachteil im Sinne des $\S 93 a$ Abs. 2 Buchstabe b BVerfGG (vgl. BVerfGE 90, $22<25$ f. >).

Das Landgericht hatte die angegriffenen Überwachungsmaßnahmen damit gerechtfertigt, dass Familienangehörige des Beschwerdeführers während der Untersuchungshaft damit begonnen hatten, Gegenstände

385 BVerfG II/2, Beschluss vom 20.6.1996 - 2 BvR 634/96 -, juris. 
aus seinem zur Zwangsversteigerung anstehenden Elternhaus zu schaffen und zu verwerten, und dass die Befürchtung bestehe, dass der erzielte Erlös den Gläubigern des Beschwerdeführers vorenthalten werden solle. Danach bestand die konkrete Gefahr, dass der Beschwerdeführer mit Hilfe von Angehörigen aus der Haft heraus Straftaten zum Nachteil seiner Gläubiger ( $§ 283$ Abs. 1 Nr. 1, $§ 288$ StGB) begehen werde. Dieser Gefahr mit geeigneten Überwachungsmaßnahmen zu begegnen, war zur Wahrung der Ordnung in der Vollzugsanstalt (§ 119 Abs. 3 StPO) nicht nur zulässig, sondern geboten (vgl. ...).“386

Auch die Protokollierung von Inhalten des Gesprächs mit einem Besucher kann hinzunehmen sein, wenn die Notwendigkeit besteht, die Kommunikation auf verschlüsselte Botschaften hin zu überprüfen (BVerfG II/3, Beschluss vom 20.4.1989 - 2 BvR 488/89 - BlStVKunde 1990, Nr2, S. 7 f.; in juris nur kurzer Orientierungssatz).

Die Anordnung der Durchsuchung eines Rechtsanwalts vor Besuchen bei einer der Baader-Meinhof-Gruppe zugehörigen Untersuchungsgefangenen, deren Interessen in urheberrechtlichen und anderen zivilrechtlichen Angelegenheiten er wahrnahm, wurde nicht als Verstoß gegen die Grundrecht des Anwalts aus Art. 12 Abs. 1 oder 2 Abs. 1 GG angesehen.

- „Die Durchsuchung des Beschwerdeführers und der von ihm mitgeführten Behältnisse verstößt nicht gegen Art. 12 Abs. 1 GG.Der Beschwerdeführer wird zwar von dieser Maßnahme in der Ausübung seines Berufes betroffen. Die Berufsausübungsfreiheit wird dadurch aber nicht eingeschränkt. Die Durchsuchung betrifft den Beschwerdeführer in gleicher Weise wie jeden anderen Besucher der Untersuchungsgefangenen und hindert ihn nicht an der sachgemäßen Ausübung seines Berufes (vgl. BVerfGE 30, $1<32>$ ). In die Freiheit der Berufsausübung würde allerdings eingegriffen, wenn sich die Anordnung der Durchsuchung auch auf eine Kenntnisnahme vom Inhalt der vom Beschwerdeführer mitgeführten Akten oder sonstigen Unterlagen erstreckte. Eine solche Wirkung ist dem Beschluß des Ermittlungsrichters jedoch nicht zu entnehmen. ... // ... Die angegriffene Entscheidung läßt auch nicht eine Herabsetzung des Beschwerdeführers in seiner Eigenschaft als Rechtsanwalt erkennen. Wie der Bundesgerichtshof in dem angegriffenen Beschluß ausdrücklich feststellt, beinhaltet die für alle geltende

386 BVerfG II/2, Beschluss vom 3.12.2007 - 2 BvR 1686/07 -, juris. 
Anordnung keinen Verdacht gegenüber dem einzelnen Besucher, sondern beruht auf der Befürchtung, daß Sympathisanten der Mandantin des Beschwerdeführers Personen, die eine Besuchserlaubnis erhalten haben, auch ohne deren Wissen zur Übermittlung von Befreiungsplänen oder Mitteln zur Selbstbefreiung mißbrauchen könnten. Die Anordnung der Durchsuchung verletzt den Beschwerdeführer auch nicht in seinem Grundrecht aus Art. 2 Abs. 1 GG.Zwar stellt eine Durchsuchung einen erheblichen Eingriff in das Recht auf freie Entfaltung der Persönlichkeit dar. Diese Maßnahme findet jedoch, wie der Bundesgerichtshof ohne Verfassungsverstoß festgestellt hat, ihre gesetzliche Grundlage in $\S 119$ Abs. 3 StPO. Die Durchsuchung des Beschwerdeführers verstößt auch nicht gegen den im Rechtsstaatsgedanken begründeten Grundsatz der Verhältnismäßigkeit. Nach den Feststellungen des Bundesgerichtshofes besteht die Gefahr, daß noch in Freiheit befindliche Mitglieder der Baader-Meinhof-Gruppe oder mit dieser Gruppe sympathisierende Personen versuchen könnten, die Mandantin des Beschwerdeführers zu befreien, und zur Übermittlung von Nachrichten oder Überbringung von Gegenständen auch dritte Personen ohne deren Wissen mißbrauchen könnten. Diese Gefahr kann nicht von vornherein mit der Begründung verneint werden, daß der Beschwerdeführer als Rechtsanwalt Organ der Rechtspflege ist und besonderen Pflichten unterliegt; denn ein solcher Mißbrauch könnte nach den Feststellungen des Bundesgerichtshofes auch ohne Wissen und Wollen des Beschwerdeführers erfol- // gen. Unter diesen Umständen ist es verfassungsrechtlich nicht zu beanstanden, daß der Bundesgerichtshof bei der gebotenen Abwägung dem Interesse an der Sicherung des Haftzweckes größeres Gewicht beigemessen hat als dem Interesse des Beschwerdeführers, die Durchsuchung nicht dulden zu müssen.“"387

\section{Medienzugang}

Die Beschränkung des Rundfunk- oder Fernsehempfangs in der Untersuchungshaft greift in das Grundrecht auf Informationsfreiheit (Art. 5 Abs. 1 Satz 1 GG) ein (BVerfGE 15, $288<293>$; 35, $1<4$ f. $>$ ). 
Der der früheren Fassung der Untersuchungshaftvollzugsordnung (Nr. 40) zugrundeliegenden Annahme, dass ein Einzelempfang des Hörfunk- oder Fernsehprogramms mittels eigenen Geräts regelmäßig mit Gefahren verbunden ist, die ein Verbot mit Erlaubnisvorbehalt rechtfertigen, ist das Bundesverfassungsgericht in einer Entscheidung aus dem Jahr 1963 nicht entgegengetreten (BVerfGE 15, $288<294>$ ); es hat aber zugleich einen grundrechtlich geschützten Rechtsanspruch auf Erteilung einer Ausnahmegenehmigung für den Fall bejaht, dass eine reale Gefährdung der eingriffsrechtfertigenden Interessen im konkreten Fall nicht vorliegt (BVerfG a.a.O. S.295; s. zum Gewicht des Grundrechts i.E. auch S. 295 ff.).

Gebilligt wurde auch, jeweils mit dem Hinweis auf die Notwendigkeit fallbezogener Abwägung (dazu allgemein o. D.I.2.a)), die Versagung der Genehmigung zum Besitz eines eigenen Fernsehgeräts, die damit begründet worden war, dass

- von dem konkreten Untersuchungsgefangenen alles ferngehalten werden müsse, was geeignet sei, Ausbruchsimpulse fördern und Anschauungsmaterial für Fluchtversuche zu liefern, und dass es daher angesichts insoweit problematischer Programminhalte mit dem Haftzweck unvereinbar sei, wenn der Beschwerdeführer unkontrolliert nach eigener Wahl das Fernsehgerät einschalten könne,

- „Das Oberlandesgericht hat nicht verkannt, daß es in jedem Einzelfall unter Beachtung der besonderen Bedeutung des Grundrechts auf Informationsfreiheit der Abwägung bedarf, ob die Versagung der Genehmigung zum Betrieb eines Fernsehgerätes unerläßlich ist, um eine reale Gefährdung der in § 119 Abs. 3 StPO aufgeführten öffentlichen Interessen zu verhindern (vgl. BVerfGE 15, 288 (295)). Das Gericht hat diese Frage aufgrund der von ihm festgestellten Umstände des konkreten Falles ohne Verfas- // sungsverstoß bejaht. Die Feststellung des Sachverhalts im einzelnen ist allein Sache des zuständigen Gerichts und kann vom Bundesverfassungsgericht nur darauf überprüft werden, ob spezifisches Verfassungsrecht verletzt ist oder Willkür vorliegt (vgl. BVerfGE 18, 85 (92)). Die vom Oberlandesgericht getroffenen Feststellungen sind unter diesem Gesichtspunkt nicht zu beanstanden. "388

388 BVerfGE 35, 307 (309 f.; zum Sachverhalt a.a.O. S. 307 f.). 
- bzw. der Betrieb eines Fernsehgeräts in der Untersuchungshaft dem Gefangenen vielfältige Möglichkeiten der Gefährdung der Sicherheit der Vollzugsanstalt eröffne, Ausnahmegründe in der Person des betroffenen Untersuchungsgefangenen nicht ersichtlich seien und aufgezeigt war, dass ihm Informationsmöglichkeiten durch Teilnahme am gemeinschaftlichen Fernsehempfang, durch Rundfunkempfang und durch Bezug von Zeitungen und Zeitschriften zur Verfügung standen (BVerfG, Vorprüfungsausschuß, Beschluss vom 25.1.1983 - 2 BvR 78/83 -, NStZ 1983, 331; in juris nur knapper Orientierungssatz).

Die besonders strengen Voraussetzungen für den Erlass einer einstweiligen Anordnung im verfassungsgerichtlichen Verfahren, die u.a. dem Verlust der Möglichkeit des Fernsehens auf dem Haftraum infolge Nichtzahlung einer Stromkostenpauschale entgegenwirken sollte, wurden ebenfalls u.a. im Hinblick auf die einstweilen bestehende Möglichkeit der Teilnahme am Gemeinschaftsfernsehen nicht als erfüllt angesehen (BVerfG II/2, Beschluss vom 26.8.2006 - 2 BvR 1652/06 - juris, betr. ebenfalls die Untersuchungshaft).

Es ist verfassungsrechtlich nicht zu beanstanden, wenn Untersuchungsgefangenen der Bezug von Büchern, Zeitungen und Zeitschriften nur durch Vermittlung der Anstalt gestattet wird (BVerfGE 34, 384 $<402$ ff. $>$, s. Auszug o. B.XIV.2.a); BVerfG, Beschluss vom 17.12.1981 2 BvR 1366/81 -, NStZ 1982, $132<$ in juris nur Orientierungssatz $>$ ).

Die richterlich angeordnete Vorenthaltung einer Ausgabe der Zeitschrift "Konkret", die einen Artikel enthielt, der sich aus Anlaß des Anschlags auf die Justizvollzugsanstalt Weiterstadt vom 27. März 1993 kritisch mit der Praxis des Strafvollzugs beschäftigte, an eine wegen versuchten Mordes - noch nicht rechtskräftig - verurteilte Untersuchungsgefangene, die Mitglied einer terroristischen Vereinigung gewesen war, wurde als Verstoß gegen Art. 5 Abs. 1 GG beanstandet wegen Nichtbeachtung des Gebots der Abwägung im Einzelfall (s.o. D.I.2.a)), da bei der Einschätzung der möglichen gefährdenden Wirkungen der Lektüre weder bisherige Erfahrungen mit der Gefangenen noch der Umstand berücksichtigt worden sei, dass die Gefangene sich von der Vereinigung, der der Anschlag zugerechnet werde, schon vor zehn Jahren distanziert habe (BVerfG II/2, Beschluss vom 2.12.1993 - 2 BvR 1368/93 - juris).

Die auf Sicherheitsgründe gestützte zahlenmäßige Beschränkung des Bezuges von Wochen- und Monatszeitschriften (im konkreten Fall: Beschränkung auf vier Titel) ist verfassungsrechtlich nicht zu beanstanden. 
- „Die Informationsfreiheit des Untersuchungsgefangenen ist durch $\S 119$ Abs. 3 StPO in verfassungsrechtlich zulässiger Weise eingeschränkt. (Art. 5 Abs. 2 GG). Das Bundesverfassungsgericht hat sich auf die Prüfung zu beschränken, ob die äußerste Grenze der dem Richter durch die StPO eingeräumten Entscheidungsmacht im Lichte des durch sie beschränkten Grundrechts überschritten ist. Das läßt sich nur feststellen, wenn die Überschreitung jener Grenze eindeutig ist (BVerfGE 35, 311 [316f.]).

Die Beschränkung des Zeitungs- und Zeitschriftenbezugs auf eine bestimmte Anzahl von Wochen- und Monatsschriften überschreitet diese Grenze nicht. Die Bestimmung der Anzahl auf jeweils vier Titel beruht auf einer Abwägung zwischen den Sicherungsbedürfnissen der Anstalt und dem Informationsinteresse des Beschwerdeführers. Sie berücksichtigt in angemessener Weise, daß die Gestattung weiterer Zeitungen und Zeitschriften nicht nur eine ins Gewicht fallende Erschwerung der inhaltlichen Kontrolle des Schriftguts mit sich brächte, sondern auch die Übersichtlichkeit des Haftraums beeinträchtigen würde.

Die richterliche Entscheidung ist auch nicht deshalb verfassungsrechtlich zu beanstanden, weil sie möglicherweise die religiöse, berufliche und pädagogische Fortbildung des Bf. behindert. Die Informationsfreiheit ist nicht zuletzt um der Fortbildung willen gewährleistet, so daß bei einer Einschränkung der Informationsfreiheit auch die vom Beschwerdeführer genannten Behinderungen berücksichtigt sind. Es kann dahinstehen, ob in einem besonderen Einzelfall das Grundrecht der Informationsfreiheit unter Beachtung der Grundentscheidung der Art. 4, 6 und 12 GG gebietet, dem Beschwerdeführer den Bezug einer bestimmten Druckschrift über den gestatteten Rahmen hinaus zu ermöglichen." 389

Zum Fernsehempfang s. auch B.XX.2. (im Kapitel zum Strafvollzug i.e.S.).

389 BVerfG II/2, Beschluss vom 17.12.1981 - 2 BvR 1366/81 -, NStZ 1982, 132; in juris nur Orientierungssatz. 
VI. Post

1. Briefverkehr

a) Allgemeines

Beschränkungen des zulässigen Briefverkehrs aus der Untersuchungshaft - der ausgehenden Briefpost - sind als Eingriffe des in das Grundrecht des betroffenen Gefangenen aus Art. 5 Abs. 1 GG (BVerfGE 34, 384 $<401>$ ) oder Art. 2 Abs. 1 GG eingeordnet worden (BVerfGE 57, 170 $<177>$; Art. 2 Abs. 1 GG wird hier offenbar als einschlägig angesehen, weil es um die „strafrechtliche Repression" von Kommunikationsverhalten geht, a.a.O. S. 202, ohne nähere Erläuterung, weshalb in solchen Fällen nicht zugleich die Meinungsfreiheit betroffen und spezialitätshalber vorrangig sein soll).

Beschränkungen des zulässigen Empfangs eingehender persönlicher Schreiben greifen dagegen nicht in das Grundrecht des Gefangenen aus Art. 5 Abs. 1 GG (BVerfGE 34, $384<399$ f.>; 35, $311<315>$ ), sondern (nur) in das Grundrecht aus Art. 2 Abs. 1 GG ein (BVerfGE 34, 384 $<399$ f. $>$; s. Auszug oben im Abschnitt zum Anhalten von Briefen im Strafvollzug, B.XIV.2.).

Eine Verstärkung des Schutzes durch die genannten Grundrechte ergibt sich für die Korrespondenz mit Angehörigen, zu denen ein von Art. 6 Abs. 1 GG geschütztes Verhältnis besteht, aus diesem Grundrecht (BVerfGE 57, 170<178>; näher im Folgenden unter b)).

Die Anordnung einer über eine einzelne Maßnahme hinausgehenden generellen Beschränkung des zulässigen Briefverkehrs von Untersuchungsgefangenen nach $\S 119$ Abs. 3 StPO a.F. wurde als mit dem Grundsatz der Verhältnismäßigkeit vereinbar angesehen, wenn und soweit eine reale Gefährdung der dort bezeichneten öffentlichen Interessen nicht jeweils durch Einzelmaßnahmen hinreichend abgewehrt werden kann (BVerfGE 34, $384<396,399$ f., 401>, betr. einen Fall, in dem u.a. die Beschränkung des Postverkehrs auf die Kommunikation mit Angehörigen und amtlichen Stellen angeordnet worden war, s. a.a.O. S. 386). Der Grundsatz der Verhältnismäßigkeit gebietet es jedoch, Ausnahmen von der generellen Beschränkung zu gestatten, wenn im konkreten Fall eine reale Gefährdung des Haftzweckes oder der Ordnung in der Anstalt ersichtlich nicht zu befürchten ist (BVerfGE 34, $384<400$ i.V.m. 397 f. >). 
Die Überwachung des Briefverkehrs greift in das Grundrecht aus Art. 10 Abs. 1 GG ein (BVerfG II/2, Beschluss vom 30.10.2014 - 2 BvR 1513/14 -, juris; vgl. auch BVerfGK 19, $140<146>$; näher im einschlägigen Abschnitt des Strafvollzugskapitels, B.XIV.1.).

Zur Verfassungsmäßigkeit der auch den Postverkehr betreffenden Kontaktsperre nach $\S \S 31 \mathrm{ff}$. EGGVG in der damaligen Fassung s. BVerfGE 49, 24 (53 ff.); näher oben im den Strafvollzug i.e.S. betreffenden Abschnitt über Besuche, B.XIII.3.

b) Beleidigende Briefe

Briefe, die das Anstaltspersonal oder sonstige Justizorgane beleidigen, können (bereits) wegen der Spannungen, die die Weiterleitung derartiger Äußerungen in der Anstalt erzeugen würde, als ordnungsgefährdend von der Weiterleitung ausgeschlossen werden.

- „Der an den Untersuchungsgefangenen gerichtete Brief kann seinem Inhalt nach durch die darin zum Ausdruck kommende Solidarisierung des Absenders mit dem Häftling für diesen eine Ermutigung sein und ihn in seinen Überzeugungen bestärken. Es ist nicht auszuschließen, daß der Empfänger durch die in dem Brief enthaltenen groben Beleidigungen - sie festzustellen und zu würdigen ist der für die Briefkontrolle zuständige Richter berechtigt, weil es nicht nur darum geht, daß er anstelle des Strafrichters oder des Zivilrichters, unter Umständen gar als Betroffener, der beleidigt wird, eine strafrechtliche oder zivilrechtliche Verurteilung ausspricht, sondern nur darum, daß er inzidenter für seine Entscheidung zur Überzeugung kommt, der Brief enthalte einen Angriff auf die Ehre eines anderen und dadurch, daß der Untersuchungsgefangene die Verfügungsgewalt über diesen Brief erhalte, werde die Ordnung in der Anstalt gestört - zur Aufsässigkeit oder zu einem aggressiven, die Anstaltsordnung störenden Verhalten gereizt oder verleitet wird. Der Brief kann also in der Hand des Adressaten zu einer realen Gefahr für die äußere Ordnung der Anstalt werden.

Entscheidend ist aber: Wenn dieser Brief seines Inhalts wegen nicht angehalten werden darf, dann müssen alle Briefe gleicher Art bei sonst gleichen Umständen unbeanstandet bleiben. Das heißt, es spricht sich herum, es wird rasch allgemein bekannt - und zwar nicht nur unter den Häftlingen, sondern auch bei allen, die aus welchen Motiven immer 
bereit sind, sich an einer Korrespondenz dieser Art zu beteiligen, und beim Anstaltspersonal, daß Briefe dieser Art ungehindert die Briefkontrolle passieren müssen. Ein solcher Zustand muß die Ordnung der Anstalt ganz emp- // findlich stören. Das Bewußtsein der Häftlinge, Anstaltsleitung und Anstaltspersonal wissen und müssen hinnehmen, daß sie, die betroffenen Richter und die Justiz in Briefen an Häftlinge und in Briefen von Häftlingen laufend herabgewürdigt und beschimpft werden, und das korrespondierende Bewußtsein der Anstaltsleitung und des Anstaltspersonals "Wir müssen uns das in diesem Haus gefallen lassen", erzeugen rasch und auf Dauer einen Zustand der Spannung zwischen Gefangenen und Anstaltspersonal; das verändert nachteilig das Auftreten und Verhalten der Gefangenen ebenso wie das des Anstaltspersonals mit der Folge, daß sich Auseinandersetzungen und Konfliktsituationen häufen. Das ist für die äußere Ordnung in der Anstalt schlechthin unerträglich. Deshalb kann der hier in Rede stehende Brief (und jeder Brief gleicher Art) im Zuge der Briefkontrolle angehalten werden.“390

Darüber hinaus können Briefe beleidigenden Inhalts grundsätzlich auch zur Verhinderung der Straftat angehalten werden, die mit dem Erreichen des Adressaten begangen würde. Das gilt allerdings nicht für Briefe des Untersuchungsgefangenen, die den besonderen Schutz der Vertraulichkeit der Kommunikation (s. dazu auch den Abschnitt zum besonderen Schutz vertraulicher Kommunikation im Strafvollzugskapitel, B.XIV.2.b)) genießen.

- „Den Fachgerichten ist es ... nicht verwehrt, eine Gefahr für die Ordnung in der Anstalt anzunehmen, wenn konkrete Anhaltspunkte dafür vorliegen, daß ein Untersuchungsgefangener dort eine Straftat begehen werde. Unter diesem Gesichtspunkt kommt auch das Anhalten eines Gefangenenbriefes ehrkränkenden Inhalts in Betracht, wenn dies dazu dient, daß die Beleidigung nicht zur Kenntnis des Adressaten der Beleidigung oder eines anderen kommt. Dies gilt jedoch dann nicht, wenn es sich um vertrauliche Kommunikation in Briefen handelt, die ein Untersuchungsgefangener an einen Familienangehörigen oder eine Person engen Vertrauens schreibt. Solche Äußerungen nehmen an dem Schutz

390 BVerfGE 35, 311 (318 f.), betr. Weiterleitung eines an einen Untersuchungsgefangenen gerichteten Briefs mit grob beleidigenden Äußerungen über die Justiz. 
der Privatsphäre des Briefschreibers teil, welcher aus dem in Art. 2 Abs. 1 GG i.V. mit Art. 1 Abs. 1 GG gewährleisteten allgemeinen Pesönlichkeitsrecht abzuleiten ist (vgl. BVerfGE 90, 255, 260).“391

Auch unsachliche Justizkritik in einem Schreiben, das dem besonderen grundrechtlichen Schutz vertraulicher Kommunikation unterliegt, ist hinzunehmen (BVerfGE 35, $35<39$ f.>).

Vertraulichkeit der Kommunikation kann in Anspruch genommen werden im Verhältnis zwischen Ehegatten

- „Das Bundesverfassungsgericht hat in ständiger Rechtsprechung anerkannt, daß das Grundgesetz dem einzelnen Bürger einen unantastbaren Bereich privater Lebensgestaltung gewährt, der der Einwirkung der öffentlichen Gewalt entzogen ist (BVerfGE 6,32 [41]; 27, 1 [6]; 27, 344 [350f.]; 32, 373 [378f.]; Beschluß vom 31.1.1973 - 2 BvR 454/71 -) .... Das verfassungskräftige Gebot der Achtung der Intimsphäre des Einzelnen hat seine Grundlage in dem durch Art. 2 Abs. 1 GG verbürgten Recht auf freie Entfaltung der Persönlichkeit. Bei der Bestimmung von Inhalt und Reichweite dieses Grundrechts ist $\mathrm{zu}$ beachten, daß nach der Grundnorm des Art. 1 Abs. 1 GG die Würde des Menschen unantastbar ist und von aller staatlichen Gewalt geachtet und geschützt werden muß.

Zwar steht nicht der gesamte Bereich des privaten Lebens unter dem absoluten Schutz des Grundrechts aus Art. 2 Abs. 1 in Verbindung mit Art. 1 Abs. 1 GG. Der Bürger, der von der Gemeinschaft abhängig und ihr verpflichtet ist, muß vielmehr staatliche Maßnahmen hinnehmen, die im überwiegenden Interesse der Allgemeinheit unter strikter Wahrung des Verhältnismäßigkeitsgebots getroffen werden, soweit sie nicht den unantastbaren Bereich privater Lebensgestaltung beeinträchtigen. Deshalb ist es auch zulässig, daß der Briefverkehr eines Untersuchungsgefange- // nen mit seinem Ehepartner der richterlichen Kontrolle unterliegt, um eine Gefährdung der in $\S 119$ Abs. 3 StPO bezeichneten öffentlichen Interessen zu verhindern.

Andererseits muß der die Briefkontrolle ausübende Richter jedoch berücksichtigen, daß dem freien brieflichen Kontakt mit dem Ehegatten im Hinblick auf das verfassungskräftige Gebot der Achtung der Intimsphäre besondere Bedeutung zukommt. Der der ehelichen Privatsphäre

391 BVerfG II/2, Beschluss vom 24.6.1996 - 2 BvR 2137/95 -, juris. 
gebührende Schutz entfällt nicht dadurch, daß der Untersuchungsgefangene von der Kontrolle seiner Briefe durch den Richter weiß.“392

und im Eltern-Kind-Verhältnis - auch wenn das Kind volljährig ist (BVerfGE 57, $170<177 \mathrm{ff} ., 178>$ ), und auch soweit die Kommunikation nicht vom Kind zu einem Elternteil, sondern vom Elternteil zum Kind verläuft; der grundrechtliche Schutz des allgemeinen Persönlichkeitsrechts erfährt insoweit eine Verstärkung durch das Grundrecht aus Art. 6 Abs. 1 GG.

- „Das Freiheitsgrundrecht des Art. 2 Abs. 1 GG erfährt durch die Verfassungsgarantie des Art. 6 Abs. 1 GG, dessen Schutzbereich auch das Verhältnis zwischen Eltern und ihren volljährigen Kindern umfaßt, eine besondere Verstärkung. Für die seelische Stabilisierung auch von erwachsenen Familienmitgliedern gewinnt das Eltern-Kind-Verhältnis in Krisensituationen der Persönlichkeit erhöhte Bedeutung. Die Familie gewährt den von öffentlicher Kontrolle freien Raum für eine entlastende Selbstdarstellung; sie trägt auch zur Erhaltung der Fähigkeit zu gesellschaftlicher Integration der Person bei. Die Gemeinschaft von Eltern und Kindern erfüllt insofern eine ähnliche Aufgabe wie die eheliche Lebensgemeinschaft (vgl. BVerfGE 57, 170<178>). Diese Verfassungsgarantien verlangen, bei der Bewertung der brieflichen Äußerungen eines Untersuchungsgefangenen die Bedeutung des Eltern-KindVerhältnisses, wie es sich im konkreten Fall darstellt, zu berücksichtigen und alle Feststellungen, die der richterlichen Antwort auf die entscheidende Frage nach der Gefährdung der Anstaltsordnung zugrunde liegen, im Lichte der angesprochenen Grundrechte zu würdigen (vgl. BVerfGE 57, $170<179>$ ).

... Das Oberlandesgericht hat ... erkennbar dem Umstand entscheidende Bedeutung zugemessen, daß im vorliegenden Falle der angehaltene Brief nicht von dem in Untersuchungshaft befindlichen volljährigen Sohn an seine Eltern, sondern vom Vater an den Sohn (und dessen Ehefrau) gerichtet worden war. Eine Einschränkung dahin, daß die vorstehend dargelegten Grundsätze in einem solchen Falle schlechthin unanwendbar seien oder daß den genannten Verfassungsgarantien bei dieser Fallgestaltung geringeres Gewicht zukäme, läßt sich jedoch der Rechtsprechung des Bundesverfassungsgerichts nicht entnehmen. Das 
Bundesverfassungsgericht hat vielmehr ausdrücklich auf die Wechselseitigkeit der Pflicht zu Beistand und Rücksichtnahme in der ElternKind-Beziehung hingewiesen (vgl. BVerfGE 57, $170<178>$ ). Das Oberlandesgericht ... hätte sich vielmehr der Erwägung öffnen müssen, daß sich auch ein älterer Mensch wie der Beschwerdeführer in einer Persönlichkeitskrise befinden kann, in der er einer durch freie Äußerungen gegenüber nahen Angehörigen zu gewinnenden Stabilisierung bedarf. Die Annahme einer solchen Krisensituation drängt sich bei dem Beschwerdeführer angesichts seiner beruflichen Katastrophe als Wirtschaftsmanager, der langen Dauer seiner Untersuchungshaft, seiner Konfrontation mit der Anklage und seiner Anspannung in einer über Monate sich hinziehenden Hauptverhandlung geradezu auf."393

Darüber hinaus genießt unabhängig von bestehenden Verwandtschaftsverhältnissen die Kommunikation mit Personen, zu denen ein ähnlich enges Vertrauensverhältnis besteht, den besonderen Schutz vertraulicher Kommunikation, der ein Anhalten von Schreiben wegen beleidigender Inhalte ausschließt.

- „Schließlich ist der Kreis möglicher Vertrauenspersonen nicht auf Ehegatten (BVerfGE 35, 35; 42, 234) oder Eltern (BVerfGE 57, 170) beschränkt. Gerade die Ausführungen in dem letztgenannten Beschluß (a.a.O., S. 178) zeigen, daß von der Funktion des Persönlichkeitsschutzes her die Übertragung auf ähnlich enge Vertrauensverhältnisse geboten ist. “394

Die Rechtsauffassung, dass die für beleidigende Inhalte im Briefverkehr von Untersuchungsgefangenen entwickelten Grundsätze auf den Briefverkehr von Strafgefangenen nicht übertragbar seien, wurde ebenso zurückgewiesen wie die Annahme, dass insoweit zwischen eingehender und ausgehender Post zu unterscheiden sei (BVerfGE 90, $255<262>$; zu den für den Strafvollzug i.e.S. entwickelten Grundsätzen s.o. B.XIV.2.b)).

393 BVerfG II/2, Beschluss vom 19.7.1990 - 2 BvR 133/90 -, juris.

394 BVerfGE 90, 255 (262); s. auch BVerfG II/2, Beschluss vom 24.6.1996 - 2 BvR 2137/95 -, juris, Auszug weiter oben. 


\section{Paketempfang}

Unter der Geltung des $\S 119$ Abs. 3 StPO a.F. wurden Beschränkungen des Empfangs von Paketen durch das im Erlasswege vorgegebene Erfordernis einer Paketmarke, auch für das in dem Erlass jeweils zu Weihnachten und zum Geburtstag grundsätzlich zugelassene Paket mit Nahrungsmitteln, nicht beanstandet.

- „Die ... Beschränkung des Paketempfangs verletzt insbesondere nicht den Grundsatz der Verhältnismäßigkeit, der die Untersuchungshaft in Anordnung wie Vollzug beherrschen muß (BVerfGE 19, 342 [347]). Eine über Einzelmaßnahmen im konkreten Fall hinausgehende generelle Beschränkung ist nach diesem Grundsatz allerdings nur zulässig, wenn eine reale Gefährdung der in $\S 119$ Abs. 3 StPO bezeichneten öffentlichen Interessen nicht jeweils durch einzelne Maßnahmen hinreichend abgewehrt werden kann. Diese Voraussetzung hat das Landgericht Bochum im vorliegenden Fall ohne Willkür bejaht. Es hat ausgeführt, daß die Vollzugsanstalt personell völlig überfordert wäre, wenn jeder Untersuchungsgefangene unbeschränkt Pakete empfangen könnte, da diese jeweils von einem Beamten in Anwesenheit des betroffenen Gefangenen im einzelnen darauf überprüft werden müßten, ob der Inhalt den Zweck der Untersuchungshaft oder die Ordnung in der Anstalt gefährde. “395

\section{Verteidigerpost}

Maßnahmen, die den freien Kontakt zwischen einem Untesuchungsgefangenen und seinem Verteidiger behindern, berühren das Recht des Gefangenen auf ein faires Verfahren (vgl. BVerfGK 19, $326<332>$, m.w.N., am Beispiel des Telefonkontakts zum Verteidiger; näher dazu im Abschnitt zu Telefonaten, unten D.VIII.).

Beschränkungen des Postverkehrs zwischen Rechtsanwalt und Mandant, die geeignet sind, das Entstehen eines Vertrauensverhältnisses zu stören, greifen darüber hinaus auch in die Berufsfreiheit des Rechtsanwalts ein.

395 BVerfGE 34, $369<380>$; zum insoweit zu berücksichtigenden Gesichtspunkt der Verallgemeinerbarkeit s.o. A.V.3. 
„Art. 12 Abs. 1 GG gewährleistet dem Rechtsanwalt eine von staatlicher Kontrolle und Bevormundung freie Berufsausübung und schützt dazu insbesondere das Vertrauensverhältnis zwischen Anwalt und Mandant (vgl. BVerfGE 113, $29<49>$ ). Integrität und Zuverlässigkeit des einzelnen Berufsangehörigen (vgl. BVerfGE 63, $266<286>$; 93, $213<236>$ ) sowie das Recht und die Pflicht zur Verschwiegenheit (vgl. BVerfGE 76, $171<190>$; 76, $196<209$ f. $>$ ) sind die Grundbedingungen dafür, dass dieses Vertrauen entstehen kann. Maßnahmen, die geeignet sind, das Entstehen eines Vertrauensverhältnisses zwischen Rechtsanwalt und Mandant zu stören oder gar auszuschließen, greifen nicht nur in die Subjektstellung des von Strafverfolgung betroffenen Mandanten, sondern auch in die Berufsausübungsfreiheit des Rechtsanwalts ein. Die Tätigkeit des Rechtsanwalts liegt dabei auch im Interesse der Allgemeinheit an einer wirksamen und geordneten Rechtspflege (vgl. BVerfGE 113, $29<49>$; BVerfG, Beschluss der 3. Kammer des Zweiten Senats vom 30. April 2007 - 2 BvR 2151/06 -, NJW 2007, S. $2752<2753>$ ). “ ${ }^{\text {396 }}$

Eine Auslegung des $§ 148$ StPO, wonach diese Bestimmung nur den unmittelbar der Verteidigung dienenden ungehinderten Verkehr zwischen Verteidiger und untersuchungsgefangenem Mandanten schützt, mit der Folge, dass ein Rechtsanwalt den Bußgeldtatbestand des §115 Abs. 1 OwiG verwirklicht, wenn er seinem Mandanten ohne Genehmigung der Kontrollstelle Schriftstücke außerhalb des in dieser Weise eng bestimmten Anwendungsbereichs des Verteidigerprivilegs aushändigt, ist nicht beanstandet worden.

- „Dabei trägt die Auslegung des Merkmals "unbefugt" im Sinne von $\S 115$ OWiG der verfassungsrechtlich verbürgten Rolle des Strafverteidigers angemessen Rechnung.

Ein unbefugtes Handeln liegt nämlich dann nicht vor, wenn sich die Weitergabe der Post im Rahmen des durch $\S 148$ StPO gestatteten ungehinderten Verkehrs zwischen dem Verteidiger und dem Beschuldigten hält. Dieser Verkehr ist jedoch nur zu Zwecken der Verteidigung frei (vgl. BVerfGE 46, $1<12>$; 49, 24, <48>; ...).

Die angegriffenen Entscheidungen begrenzen die Reichweite dieses freien Verteidigerverkehrs dahingehend, dass der unkontrollierte Ver-

396 BVerfG II/2, Beschluss vom 13.10.2009 - 2 BvR 256/09 -, juris. 
kehr nur in der Weise ausgeübt werden kann, als er unmittelbar der Vorbereitung der Verteidigung dient, mithin nur solche Schriftstücke umfasst, die unmittelbar das Strafverfahren betreffen (vgl. ebenso BGHSt 26, $304<307 \mathrm{f}$. $>$; ...). Dies ist verfassungsrechtlich nicht $\mathrm{zu}$ beanstanden.

Der weitergehenden Ansicht, wonach das Verteidigerprivileg auch Schriftsätze aus anderen Verfahren umfasse, wenn diese mit der Verteidigung in einem unmittelbaren Zusammenhang stehen oder mittelbar die Stellung des Beschuldigten im Strafverfahren tangieren (vgl. ...) zu folgen, würde bedeuten, dem Beschuldigten nahezu unkontrollierten Schriftverkehr zu ermöglichen. Diese Ansicht nimmt an, dass Bemühungen um den Erhalt oder die Beschaffung von Arbeitsplatz und Wohnung, Darlehnsaufnahme für eine Kaution und Verkauf von Wertgegenständen für die Kaution durchaus die Haftgründe oder die Sanktionsentscheidung betreffen können und damit mittelbar der Verteidigung dienen (vgl. ...). Da im Rahmen der Strafzumessung sowie der Entscheidung über die Strafaussetzung zur Bewährung mannigfaltige, in der Person des Beschuldigten liegende Gründe eine Rolle spielen, stünde bei einem derartigen Verständnis des freien Verteidigerverkehrs nahezu jedes Schreiben in irgendeinem Bezug zum Strafverfahren und im Zusammenhang mit der Verteidigung. Die Zuordnung zur eigentlichen Verteidigungsvorbereitung wäre nicht mehr eingrenzbar und würde ins Uferlose führen (vgl. ...).

Ein solch weites Verständnis des freien Verteidigerverkehrs geriete zudem in Konflikt mit dem Ziel der angeordneten Postkontrolle. Diese in $\S 119$ Abs. 3 StPO wurzelnde Beschränkung dient der Wahrung des Zwecks der Untersuchungshaft und der Ordnung in der Vollzugsanstalt (vgl. BVerfGE 35, $311<316>$ ). Da unter dem Rechtsbegriff "Ordnung in der Vollzugsanstalt" nicht nur ein Mindestmaß an Ordnung zu verstehen ist (vgl. BVerfGE 35, $311<317>$ ), kann dieses Ziel nur bei einer wirkungsvollen Ausübung der Postkontrolle erfüllt werden (vgl. ...). “397

Der besondere Schutz, unter dem die Kommunikation mit dem Verteidiger steht, entfällt nicht dadurch, dass der Untersuchungsgefangene der Sichtkontrolle des Inhalts eines Briefes, dessen Eigenschaft als Verteidigerpost 
geklärt ist, auf Aufforderung zwecks Vermeidung einer Vorenthaltung oder Verzögerung der Aushändigung zustimmt.

- „Das Oberlandesgericht selbst hat aufgrund der Feststellungen des Landgerichts angenommen, dass mit der erfolgten Rückfrage beim Absender des Briefes, um den es hier geht, dessen Eigenschaft als Verteidigerpost geklärt war und der Brief daher gemäß $§ 24$ Abs. 2 Satz 1 JVollzGB III BW nicht der Überwachung unterlag, mit der Folge grundsätzlicher Unzulässigkeit einer Öffnung des Schreibens. Nach dieser Feststellung war die Anstalt auch nicht berechtigt, dem Beschwerdeführer das Schreiben vorzuenthalten, sondern verpflichtet, es ihm ungeöffnet auszuhändigen, und daher jedenfalls aus diesem Grund auch nicht berechtigt, die Aushändigung davon abhängig zu machen, dass der Beschwerdeführer sich mit einer Sichtkontrolle einverstanden erklärte.

Kommt der Gefangene einer entsprechenden unberechtigten Aufforderung durch Vollzugsbeamte gleichwohl nach, um die Vorenthaltung oder verzögerte Aushändigung von Verteidigerpost zu vermeiden, so kann von einem frei erteilten Einverständnis, das den Anforderungen an einen wirksamen // fallbezogenen Verzicht auf die Grundrechtsausübung entspräche (vgl. ...) oder geeignet wäre, ein späteres Rechtsschutzgesuch als rechtsmissbräuchlich erscheinen zu lassen, keine Rede sein. ... Ob die angegriffenen Entscheidungen Grundrechte des Beschwerdeführers noch aus weiteren Gründen und in weiteren Hinsichten verletzen, bedarf angesichts des festgestellten Verstoßes keiner Entscheidung.

Insbesondere bleibt offen, ob eine im Hinblick auf sein eigenes Grundrecht aus Art. 10 Abs. 1 GG eingriffsausschließende Einwilligung eines Gefangenen in die Kontrolle seiner Verteidigerpost unabhängig von den eben genannten Gründen auch deshalb ausscheidet, weil die Postkontrolle zugleich Rechte des Verteidigers berührt (vgl. ...).“398

Zur Verfassungsmäßigkeit der auch die Kommunikation mit dem Verteidiger betreffenden Kontaktsperre nach $\S \S 31 \mathrm{ff}$. EGGVG in der damaligen Fassung s. BVerfGE 49, 24 (53 ff.); näher oben im den Strafvollzug i.e.S. betreffenden Abschnitt über Besuche, B.XIII.3.

398 BVerfGK 19, 140 (147 f.); s. auch bereits o. unter A.V.1. 


\section{Vermeidung von Verzögerungen durch die Postkontrolle}

Die Justizvollzugsanstalt und der mit der Briefkontrolle befasste Haftrichter sind verpflichtet, eine auch im Falle fristgebundener Schriftsätze an Gerichte für erforderlich gehaltene Briefkontrolle so zügig wie möglich durchzuführen und die mit der Kontrolle verbundenen Verzögerungen möglichst - etwa durch eine Übermittlung des Schreibens per Telefax gering zu halten (BVerfGK 12, $422<423>$; dazu und allgemein zum Gebot zügiger Postweiterleitung s.o. B.XIV.1.a)).

\section{Gegenstände im Haftraum}

Die Versagung des Besitzes eines Gegenstandes auf dem Haftraum des Untersuchungsgefangenen auf der Grundlage des $\S 119$ Abs. 3 StPO a.F. erforderte konkrete Anhaltpunkte für eine Gefährdung des Haftzwecks oder der Ordnung in der Anstalt.

- „Die Auferlegung einer Beschränkung ist bei einer den Grundrechten Rechnung tragenden Auslegung von $\S 119$ Abs. 3 StPO nicht schon dann zulässig, wenn ein möglicher Mißbrauch eines Freiheitsrechts nicht völlig auszuschließen ist. Vielmehr müssen konkrete Anhaltspunkte dafür vorliegen, daß der Untersuchungsgefangene einen ihm überlassenen Gegenstand mißbrauchen und dadurch den Haftzweck oder die Ordnung in der Anstalt gefährden könnte. “399

Die Unschuldsvermutung schließt eine Berücksichtigung des Straftatverdachts im Rahmen der Gefährdungsprognose nicht aus (näher dazu bereits D.I.4.). Die Versagung des Besitzes einer Schreibmaschine wegen einer allein hieraus abgeleiteten Gefahr des Missbrauchs zur Flucht verletzt jedoch das Gebot, alle Umstände des Einzelfalles abzuwägen.

- „Das Oberlandesgericht hat das grundrechtliche Gebot der Abwägung im Einzelfall verkannt, indem es sich mit der Feststellung begnügte, die Möglichkeit eines Mißbrauchs sei angesichts der dem Beschwerdeführer zur Last gelegten Taten und seiner Verurteilung in erster Instanz nicht auszuschließen. Die zugunsten des Untersuchungsgefangenen geltende Unschuldsvermutung steht allerdings einer Berücksichtigung 
des dringenden Verdachts, bestimmte Straftaten begangen zu haben, im Rahmen der Beurteilung der Gefährlichkeit nicht entgegen. Die Tatsache, daß ein Untersuchungsgefangener des Raubes und räuberischer Erpressung verdächtig und deshalb in erster Instanz zu einer Freiheitsstrafe von 5 Jahren verurteilt worden ist, läßt jedoch nicht ohne weiteres darauf schließen, daß er den Besitz einer Schreibmaschine zur Flucht mißbrauchen könnte. Entgegen dem von ihm selbst genannten Maßstab ist das Oberlandesgericht nicht von der individuellen Persönlichkeit des Beschwerdeführers, sondern offenbar von der allgemeinen Annahme ausgegangen, daß ein wegen solcher Straftaten zu hoher Freiheitsstrafe verurteilter Gefangener in jedem Falle zu Fluchtversuchen und zum Mißbrauch ihm über- // lassener Gegenstände zu diesem Zweck neigt, ohne auch nur diese allgemeine Annahme näher zu begründen.

Damit hat das Oberlandesgericht das grundrechtliche Gebot, alle Umstände des Einzelfalles abzuwägen, verletzt.“400

Zudem ist jeweils die Möglichkeit der Gefahrenvermeidung durch mildere Mittel wie regelmäßige Überprüfungen (vgl. BVerfGE 35, $5<10 \mathrm{f}$. $>$ ) oder Verplombung (vgl., eine elektrische Schreibmaschine betreffend, BVerfG II/2, Beschluss vom 25.7.1994 - 2 BvR 806/94 -, juris) zu prüfen. Dabei kann allerdings auch die Zumutbarkeit des mit dem Einsatz milderer Mittel verbundenen Kontrollaufwandes berücksichtigt werden (BVerfG II/2, ebd., sowie ausführlich B.XXI.1.).

Als gemäß $§ 119$ Abs. 3 a.F. StPO zulässige Einschränkung der Informationsfreiheit wurde mit Blick auf die begrenzte verfassungsgerichtliche Überprüfbarkeit fachgerichtlicher Sachverhaltsfeststellungen die Versagung des Besitzes eines eigenen Fernsehgeräts auf dem Haftraum im Fall eines Untersuchungsgefangenen angesehen, von dem die angegriffene gerichtliche Entscheidung angenommen hatte, dass angesichts von Persönlichkeitsmerkmalen, die einen Ausbruchsversuch als nicht unwahrscheinlich erscheinen ließen, alles von ihm ferngehalten müsse, was Ausbruchsimpulse fördern und Anschauungsmaterial für Fluchtversuche liefern würde; die unter dieser Voraussetzung erforderliche ständige vorherige Überprüfung des Fernsehprogramms gehört nicht mehr zu hinzunehmenden „Lästigkeiten“, dh. zu dem der Anstalt abzuverlangenden Kontrollauf-

400 BVerfGE 35, 5 (10 f.); s. auch bereits unter D.I.2.a) und D.I.3. 
wand (vgl. BVerfGE 35, $307<308$ ff.>; zum Fernsehempfang s. bereits B.XX.2.).

Für die grundrechtliche Beurteilung von Fragen des Besitzes von Gegenständen auf dem Haftraum ist, soweit es nicht um Spezifika des Untersuchungshaftvollzuges geht, die gesamte bereits im Kapitel zum Strafvollzug im engeren Sinne (B.XXI.) dargestellte Rechtsprechung heranzuziehen.

\section{Telefonate}

Die Überwachung der Telefonate eines Untersuchungsgefangenen zur Sicherung der Ordnung der Anstalt begegnet keinen grundsätzlichen verfassungsrechtlichen Bedenken. Sie kann zulässigerweise u.a. dann angeordnet werden, wenn Anhaltspunkte für die Begehung von Straftaten aus der Haft heraus mit Hilfe von Familienangehörigen bestehen. Soweit eine Überwachung zulässigerweise angeordnet ist, kann - auch soweit der Kontakt mit Familienangehörigen betroffen ist - auch die Häufigkeit und Dauer der Telefonate auf ein der Anstalt, auch unter dem Gesichtspunkt der Verallgemeinerbarkeit, organisatorisch und personell zumutbares Maß beschränkt werden.

- „Das Landgericht hatte die angegriffenen Überwachungsmaßnahmen damit gerechtfertigt, dass Familienangehörige des Beschwerdeführers während der Untersuchungshaft damit begonnen hatten, Gegenstände aus seinem zur Zwangsversteigerung anstehenden Elternhaus zu schaffen und zu verwerten, und dass die Befürchtung bestehe, dass der erzielte Erlös den Gläubigern des Beschwerdeführers vorenthalten werden solle. Danach bestand die konkrete Gefahr, dass der Beschwerdeführer mit Hilfe von Angehörigen aus der Haft heraus Straftaten zum Nachteil seiner Gläubiger ( 283 Abs. 1 Nr. 1, § 288 StGB) begehen werde. Dieser Gefahr mit geeigneten Überwachungsmaßnahmen zu begegnen, war zur Wahrung der Ordnung in der Vollzugsanstalt (§ 119 Abs. 3 StPO) nicht nur zulässig, sondern geboten (vgl. ...) ...

Die Verfassungsbeschwerde kann danach auch hinsichtlich der vom Beschwerdeführer begehrten zeitlich uneingeschränkten Nutzung eines Telefons keinen Erfolg haben, obwohl von den diesbezüglich vorgesehenen Beschränkungen auch die Kommunikation mit seinen Angehörigen betroffen ist. Art. 6 Abs. 1 GG fordert die Ermöglichung familiärer 
Kontakte nur im Rahmen des für die Anstalt unter Berücksichtigung der räumlichen und personellen Gegebenheiten Zumutbaren (BVerfGE $42,95<100$ f. $>$; vgl. auch BVerfGE 34, $369<380>$ ). Das Oberlandesgericht durfte davon ausgehen, dass eine trotz - rechtmäßig - vorgesehener akustischer Überwachung beliebig häufige und beliebig lange Nutzung eines Anstaltstelefons durch den Beschwerdeführer den Vollzugsdienst organisatorisch und personell überfordern würde (zur insoweit berücksichtigungsfähigen Verallgemeinerbarkeit im Hinblick auf andere Gefangene, die bei gleicher Sachlage gleiche Behandlung ihrer Anliegen beanspruchen können, vgl. BVerfG, Beschluss der 2. Kammer des Zweiten Senats vom 31. März 2003 - 2 BvR 1848/02 -, NJW 2003, S. $2447<2448>$ ). “401

Die Überwachung von Telefonaten mit dem Verteidiger berührt das grundrechtlich geschützte Recht des Untersuchungsgefangenen auf ein faires Verfahren. Dieses Recht ist verletzt, wenn die es ausgestaltenden Normen der Strafprozessordnung missachtet werden.

- „Maßnahmen, die den freien Kontakt zwischen dem Beschuldigten und seinem Verteidiger behindern, berühren das Recht auf ein faires Verfahren (vgl. BVerfGE 49, $24<55>$ ), das seine Grundlage im Grundrecht auf freie Entfaltung der Persönlichkeit aus Art. 2 Abs. 1 GG in Verbindung mit dem Rechtsstaatsprinzip hat (vgl. BVerfGE 26, 66 $<71>$; 38, $105<111>$; 40, $95<99>$; 65, $171<174>$; 66, $313<318>$; 77, $65<76>$; 86, $288<317>$ ). Das Recht auf ein faires Verfahren, dem in vieler Hinsicht auf unterschiedliche Weisen Rechnung getragen werden kann, in einer den sachlichen Gegebenheiten angemessenen Weise zu konkretisieren, ist in erster Linie Sache des Gesetzgebers (vgl. BVerfG, // Beschluss der 2. Kammer des Zweiten Senats vom 8. Juni 2010 - 2 BvR 432/07 u.a. -, NJW 2011, S. $591<592$ f.>). Werden die das Recht auf ein faires Verfahren ausgestaltenden Vorschriften der Strafprozessordnung missachtet oder berücksichtigen die Gerichte bei ihrer Auslegung und Anwendung nicht hinreichend die Tragweite des Rechtsstaatsgebots, so ist das Recht auf ein faires Verfahren verletzt

401 BVerfG II/2, Beschluss vom 3.12.2007 - 2 BvR 1686/07 -, juris. 
(vgl. zu den Vorschriften über die Mitwirkung des Verteidigers BVerfGE $65,171<174,175$ f. $>$; 66, $313<318,319$ f.>). “402

Als Verletzung des Rechts auf ein faires Verfahren wurde daher die Ablehnung der von einem ortsfremden Verteidiger zur Vorbereitung eines Schriftsatzes beantragten richterlichen Genehmigung für ein fernmündliches Gespräch mit seinem untersuchungsgefangenen Mandanten angesehen, die damit begründet worden war, dass solche Gepräche nur aus gewichtigem Grund genehmigungsfähig seien, weil sie aus Sicherheitsgründen nur in einem Dienstzimmer in Anwesenheit eines Vollzugsbeamten geführt werden könnten und daher bei großzügigerer Zulassung mit sicherheitsgefährdendem Aufwand verbunden wären, und weil zudem nicht sicher feststellbar sei, ob es sich bei dem Gesprächspartner tatsächlich um den Verteidiger handele. Nach den geltenden das Recht auf ein faires Verfahren ausgestalteten Vorschriften konnte die Genehmigung jedenfalls nicht mit der Begründung versagt werden, dass Telefonate mit dem Verteidiger grundsätzlich zu überwachen seien.

- „Der Gesetzgeber hat das Recht des Beschuldigten auf ein faires Verfahren mit $\S 148$ Abs. 1 StPO dahingehend konkretisiert, dass auch dem inhaftierten Beschuldigten schriftlicher und mündlicher Verkehr mit dem Verteidiger gestattet ist. Eine - eng auszulegende (vgl. ...) Ausnahme sieht $\S 148$ Abs. 2 StPO lediglich für Fälle des dringenden Verdachts einer Straftat nach $\S 129$ a StGB, auch in Verbindung mit $\S 129 \mathrm{~b}$ StGB, vor. Unabhängig von der Frage, inwieweit dies Beschränkungen der Häufigkeit telefonischer Kontaktaufnahme zwischen dem Beschuldigten und seinem Verteidiger aus Gründen der Anstaltsordnung zulässt (vgl. ...), ist danach für die nicht von $§ 148$ Abs. 2 StPO erfassten Fälle jedenfalls eine Überwachung stattfindender Telefonate zwischen einem Beschuldigten und seinem nicht selbst tat- oder teilnahmeverdächtigen Verteidiger ausgeschlossen (vgl. ...).

Die Neufassung des $§ 119$ Abs. 1 StPO durch das Gesetz zur Änderung des Untersuchungshaftrechts vom 29. Juli 2009 (BGB1 I S. 2274), gemäß dessen Art. 8 Abs. 1 in Kraft getreten am 1. Januar 2010, hat daran nichts geändert. §119 Abs. 1 StPO n.F. ermöglicht Beschränkungen der Telekommunikation von Untersuchungsgefangenen zur Ab-

402 BVerfGK 19, 326 (332 f.); hierauf Bezug nehmend BVerfG II/3, Beschluss vom 3.12.2013 - 2 BvR 2299/13 - juris, betr. Telefonate eines Sicherungsverwahrten mit dem Verteidiger. 
wehr einer Flucht-, Verdunkelungs- oder Wiederholungsgefahr. § 119 Abs. 4 Satz 1 StPO n.F. bestimmt jedoch ausdrücklich, dass die $\S \S 148$, 148a StPO unberührt bleiben. Damit wird // klargestellt, dass Maßnahmen nach $\S 119$ Abs. 1 StPO n.F., soweit sie den durch $\S 148$ Abs. 1 StPO garantierten freien Verkehr des Gefangenen mit seinem Verteidiger einschränken würden, nach wie vor nur in dem durch $\S 148$ Abs. 2 StPO bestimmten Ausmaß zulässig sind (vgl. BTDrucks 16/11644, S. 28).

Unabhängig von der durch die angegriffenen Beschlüsse nicht beantworteten Frage, ob als Rechtsgrundlage der hier umstrittenen Beschränkung § 119 Abs. 1 StPO n.F. oder der zum Zeitpunkt der angegriffenen Entscheidungen im Freistaat Bayern gemäß Art. 125a Abs. 1 GG als Rechtsgrundlage für haftvollzugsrechtliche Maßnahmen fortgeltende $\S 119$ Abs. 3 StPO a.F. in Betracht kam (zum kompetenzrechtlichen Hintergrund, zur Abgrenzung zwischen strafverfahrenssichernden und haftvollzugsrechtlichen Eingriffsgrundlagen und zu möglichen Überschneidungen vgl. BTDrucks 16/11644, S. 23), konnte daher die angegriffene Versagung des Telefonkontakts zwischen der Beschwerdeführerin und ihrem Verteidiger jedenfalls nicht - ohne jede Auseinandersetzung mit den Vorgaben des $\S 148$ StPO - mit der Erwägung gerechtfertigt werden, Telefongespräche zwischen Gefangenen und ihrem Verteidiger seien allgemein nur unter Überwachung zuzulassen und daher wegen des damit verbundenen organisatorischen und personellen Aufwandes aus einem Anlass der von der Beschwerdeführerin angeführten Art nicht genehmigungsfähig. “ “403

Ein nicht näher begründeter Verweis darauf, dass die Identität der telefonischen Kontaktperson mit dem Verteidiger nicht ausreichend sicher feststellbar sei, rechtfertigt die Versagung der Genehmigung eines Telefonkontakts mit dem Verteidiger nicht, zumal dabei nicht berücksichtigt ist, dass dem Strafverteidiger ein Vertrauensvorschuss zuzubilligen ist.

- „Soweit die angegriffenen Entscheidungen sich darauf berufen, dass nicht in der gebotenen Weise sicherzustellen sei, ob es sich bei einem telefonischen Gesprächspartner tatsächlich um den Verteidiger handele, ist dies jedenfalls nicht ohne nähere Darlegung nachvollziehbar. Die gewünschte telefonische Verbindung kann unter Nutzung der Telefon- 
nummer, die der als solcher ausgewiesene Verteidiger angegeben hat, von der Justizvollzugsanstalt selbst hergestellt werden. Die Annahme, es sei grundsätzlich nicht hinreichend gewährleistet, dass es sich bei einer auf diesem Wege erreichten Person, die der Verteidiger zu sein behauptet, tatsächlich um den Verteidiger handelt, bedürfte näherer Begründung, die sich auch damit auseinanderzusetzen hätte, dass der Strafverteidiger kraft seiner Stellung als Organ der Rechtspflege nach geltendem Recht einen Vertrauensvorschuss genießt (vgl. BVerfG, Beschluss der 1. Kammer des Zweiten Senats vom 5. Januar 2006 2 BvR 2/06 -, NJW 2006, S. $1500<1501>$; vgl.auch EGMR, Urteil vom 28. November 1991, S../. Schweiz, Beschwerde Nr. 12629/87 u.a., Rn. 48; Urteil vom 25. März 1992, Campbell./. Vereinigtes Königreich, Beschwerde Nr. 13590/88, Rn. 46; Urteil vom 12. Mai 2005, Öcalan./. Türkei, Beschwerde Nr. 46221/99, Rn. 133; Urteil vom 13. März 2007, Castravet // ./. Moldawien, Beschwerde Nr. 23393/05, Rn. $49 \mathrm{f} . ;$...).“ “404

$\mathrm{Zu}$ berücksichtigen wären zudem der Anspruch auf Vertraulichkeit der Verteidigerkommunikation und - im Hinblick auf die besonders einschneidenden Wirkungen der Versagung telefonischer Kommunikation, wo es, wie im konkreten Fall, um den Kontakt mit einem ortsfremden Verteidiger geht (s.o.) - das Recht auf freie Wahl des Verteidigers $(\S 137$ StPO).

- „Die Gerichte haben sich darüber hinaus auch mit der Frage, inwieweit schon die Darlegungslast, die Beschuldigten beziehungsweise ihren Verteidigern mit der Beschränkung wechselseitigen Telefonkontakts auf besonders zu begründende Dringlichkeitsfälleauferlegt wird, mit dem Anspruch auf Vertraulichkeit der Verteidigerkommunikation in Konflikt gerät, sowie mit der Bedeutung telefonischer Kontaktmöglichkeiten für die Effektivität des vom Recht auf ein faires Verfahren umfassten (vgl. BVerfGE 34, $293<302>$; 38, $105<111$ f. $>$; 39, 156 $<163>$; 66, $313<319>$; 68, $237<255>$; 110, $226<253>$ ) und in $\S 137$ StPO einfachgesetzlich verankerten Rechts auf freie Wahl des Verteidigers nicht auseinandergesetzt. “405 
Zur Privatisierbarkeit des Betriebs der für Gefangene nutzbaren Telefonanlage und der insoweit aus der Fürsorgepflicht der Vollzugsanstalt folgenden Verpflichtung zur Wahrung der wirtschaftlichen Interessen der Gefangenen s. BVerfGK 17, 415 ff. (näher im Abschnitt zur Privatisierbarkeit von Aufgaben des Strafvollzuges, B.IV.).

\section{Besondere Sicherungsmaßnahmen}

Die für Beschränkungen auf der Grundlage der Generalklausel des $§ 119$ Abs. 3 StPO a.F. geltenden Anforderungen an die Verhältnismäßigkeit des Eingriffs (s.o. D.I.2. und D.I.3.), insbesondere das Erfordernis der Abwägung aller Umstände des Einzelfalls, hat das Bundesverfassungsgericht insbesondere auch in Bezug auf die Anordnung besonderer Sicherungsmaßnahmen zur Geltung gebracht.

- „Für die Auslegung des $\S 119$ Abs. 3 StPO und die Prüfung der Voraussetzungen für eine Beschränkung nach dieser Bestimmung ist entscheidend, dass der Grundsatz der Verhältnismäßigkeit, der den Vollzug der Untersuchungshaft in besonderem Maße beherrschen muss (vgl. BVerfGE 34, $369<380>$; 35, $5<9>$; 35, $307<309>$ ), eine Abwägung aller Umstände des Einzelfalles gebietet (vgl. BVerfGE 35, 5 $<11>$ ). Beschränkungen sind danach nur zulässig, wenn sie erforderlich sind, um eine reale Gefahr für die in $\S 119$ Abs. 3 StPO genannten öffentlichen Interessen abzuwehren, und dieses Ziel nicht mit weniger eingreifenden Maßnahmen erreicht werden kann (vgl. BVerfGE 35, 5 $<9$ f.>; 35, $311<321>$ ). Für eine Gefährdung des Haftzwecks oder der Ordnung in der Anstalt müssen konkrete Anhaltspunkte vorliegen (vgl. BVerfGE 35, $5<10>$; 42, $234<236>$; 57, $170<177>$; BVerfG, Beschluss der 2. Kammer des Zweiten Senats vom 6. November $2007-2$ BvR 1136/07 -, www.bverfg.de). Danach sind den durch § 119 Abs. 3 StPO eröffneten Möglichkeiten des Eingriffs in Grundrechte des Untersuchungsgefangenen auch bei voller Ausschöpfung der Generalklausel vergleichsweise enge Grenzen gesetzt (vgl. BVerfG, Beschlüsse der 2. Kammer des Zweiten Senats vom 25. Juli 1994 - 2 BvR 806/94 -, StV 1994, S. $585<586>$; und vom 19. Juli 1995 - 2 BvR 1439/95 -, StV 1995, S. 536).

Gestützt auf $\S 119$ Abs. 3 StPO kommen besondere Sicherungsmaßnahmen namentlich in Betracht, wenn nach dem Verhalten des Gefan- 
genen oder aufgrund seines seelischen Zustandes in erhöhtem Maße Fluchtgefahr, die Gefahr von Gewalttätigkeiten gegen Personen oder Sachen oder die Gefahr der Selbsttötung oder Selbstbeschädigung besteht (vgl. Nr. 60 Abs. 2 UVollzO). Auch bei der Entscheidung über die Anordnung und Aufrechterhaltung besonderer Sicherungsmaßnahmen ist der Grundsatz der Verhältnismäßigkeit zu beachten (vgl. für den Strafvollzug BVerfG, Beschluss der 2. Kammer des Zweiten Senats vom 13. April 1999 - 2 BvR 827/98 -, StV 1999, S. $551<552>$ ). Danach bedarf es konkreter Anhaltspunkte für das Vorliegen einer gesteigerten Gefährdungslage im vorerwähnten Sinn (vgl. ...), und die angeordneten Maßnahmen müssen zur Gefahrenabwehr geeignet und erforderlich sein (vgl. ...).“406

Die Unterbringung in einem besonders gesicherten Haftraum mit permanenter Videoüberwachung und vollständiger Entkleidung berührt das Grundrecht aus Art. 2 Abs. 1 i.V.m. Art. 1 Abs. 1 GG. Die Wegnahme einzelner Kleidungsstücke kann als besondere Sicherungsmaßnahme zur Suizidvorbeugung gerechtfertigt sein; geboten ist aber die Bereitstellung von in der gegebenen Situation ungefährlicher Ersatzkleidung.

- „Im Hinblick auf die Ausstrahlungswirkung des Art. 1 Abs. 1 GG auf den Inhalt des allgemeinen Persönlichkeitsrechts und die hieraus resultierende besondere Wertigkeit dieses Schutzgutes (vgl. BVerfGE 27, $344<351>$; 32, $373<379>$; 34, $238<245>$; 54, $148<153>$; 79, 256 $<268>$ ) berührt die Unterbringung in einem besonders gesicherten Haftraum mit permanenter Videoüberwachung bei vollständiger Entkleidung die durch Art. 2 Abs. 1 in Verbindung mit Art. 1 Abs. 1 GG geschützte Intimsphäre des Betroffenen. ...

Auch die Grundrechte Gefangener dürfen nur durch Gesetz oder aufgrund Gesetzes und nur unter Beachtung des Grundsatzes der Verhältnismäßigkeit eingeschränkt werden (vgl. BVerfGE 33, $1<11>$; 89, 315 $<322 \mathrm{f}$. $>$ ). Die als besondere Sicherungsmaßnahme in $\S 88$ Abs. 1, Abs. 3 in Verbindung mit Abs. 2 Nr. 5 StVollzG vorgesehene Unterbringung in einem besonders gesicherten Haftraum mit permanenter Videoüberwachung stellt schon für sich genommen einen erheblichen Eingriff in grundrechtlich geschützte Rechtspositionen dar (vgl.

406 BVerfG, Beschluss der 2. Kammer des Zweiten Senats vom 24. Januar 2008 - 2 BvR 1661/06 -, juris. 
BVerfG, Beschlüsse der 2. Kammer des Zweiten Senats vom 13. April 1999 - 2 BvR 827/98 -, NStZ 1999, S. $428<429>$ und vom 24. Januar 2008 - 2 BvR 1661/06 -, juris, Rn. 50). Die Wegnahme einzelner Kleidungsstücke kann in diesem Zusammenhang nach $\S 88$ Abs. 1, Abs. 3 in Verbindung mit Abs. 2 Nr. 1 StVollzG zur Abwendung erheblicher Gefahren für den Gefangenen, insbesondere Suizid, zwar gerechtfertigt sein (vgl. ...). Die Erheblichkeit des Eingriffs und der verfassungsrechtlich gebotene Grundsatz der Verhältnismäßigkeit erfordern aber grundsätzlich, dem Gefangenen unmittelbar und gleichzeitig mit der Entkleidung Ersatzkleidung aus schnell reißendem Material zur Verfügung zu stellen, um ihm ein Mindestmaß an Intimsphäre zu bewahren und ihn nicht zum bloßen Objekt des Strafvollzuges zu degradieren (vgl. ...). “407

Bei der Beurteilung der Verhältnismäßigkeit besonderer Sicherungsmaßnahmen können Art und Schwere der Taten, die dem Betroffenen vorgeworfen werden, berücksichtigt werden. Handelt es sich um Bandenkriminalität, so liegt eine - geeignete Gegenmaßnahmen rechtfertigende - Verdunkelungsgefahr nahe.

- „Dem Beschwerdeführer liegen die Verbrechen des schweren Bandendiebstahls (§ 244a StGB) und der gewerbsmäßigen Bandenhehlerei (§ 260a StGB) zur Last. Es liegt in der Natur banden- und gewerbsmäßig begangener Verbrechen, daß Täter und Teilnehmer bei jeder Art des Zusammenwirkens auf konspirative Verhaltensweisen angewiesen sind, um Entdeckung und Strafverfolgung zu verhindern. Es entspricht kriminalistischer Erfahrung, daß solche Verhaltensweisen häufig auch nach der Festnahme in der Haft mit dem Ziel fortgesetzt werden, den Umfang des jeweils eigenen Tatbeitrags zu verschleiern, Mitgefangene zu abschwächenden Aussagen zu veranlassen, in Freiheit befindliche Tatbeteiligte zu decken und auf Belastungszeugen - insbesondere auch mittelbar durch Dritte - in unlauterer Weise einzuwirken. Daher besteht in Fällen der Verbrechensart, die dem Beschwerdeführer angelastet wird, regelmäßig die Gefahr, daß die Ermittlung des wahren Sachverhalts im Strafverfahren erschwert oder behindert wird.

Diese den angegriffenen Entscheidungen zugrundeliegende Einschätzung wird bestätigt durch die Feststellung, daß einige - ebenfalls in-

407 BVerfG II/2, Beschluss vom 18. März 2015 - 2 BvR 1111/13 -, juris. 
haftierte - Tatgenossen des Beschwerdeführers Kassiber austauschten, um verfahrensbezogene Absprachen zu treffen. Nach alledem begegnet die Ansicht der Fachgerichte, daß bei dem Beschwerdeführer ein besonders hohes Maß an Verdunklungsgefahr bestehe, keinen Bedenken. Die angeordneten Maßnahmen sind geeignet und auch erforderlich, um dieser Gefahr zu begegnen. Insbesondere ist in dem vom Landgericht bestimmten Umfang die Gesamtheit aller Maßnahmen notwendig, um die Kontaktaufnahme des Beschwerdeführers mit anderen Tatbeteiligten - die auch von diesen ausgehen kann - sicher zu unterbinden. Angesichts der Schwere der dem Beschwerdeführer zur Last gelegten Taten, die in der Regelstrafandrohung von einem Jahr bis zu zehn Jahren Freiheitsstrafe zum Ausdruck kommt, kann derzeit die Unzumutbarkeit der zulässig (...) angegriffenen Maßnahmen auch unter Berücksichtigung ihres kumulierenden Zusammenwirkens mit den anderen Vorkehrungen nicht festgestellt werden. Sie bewegen sich im Rahmen dessen, was ein Untersuchungsgefangener bei einem schweren Tatvorwurf hinnehmen muß.“408

Dass der Vollzugsbehörde (auch) in Bezug auf die Anordnung besonderer Sicherungsmaßnahmen für die Gefahrenprognose ein Beurteilungsspielraum eingeräumt wird, ist verfassungsrechtlich nicht zu beanstanden.

- „Bei der prognostischen Einschätzung der Gefährdungslage gemäß $\S 119$ Abs. 3 StPO, Nr. 62 UVollzO wird der Vollzugsbehörde - ohne Verfassungsverstoß - ein Beurteilungsspielraum zugebilligt, in dessen Rahmen sie bei Achtung der Grundrechte des Gefangenen eine von mehreren Entscheidungen treffen kann, die gleichermaßen rechtlich vertretbar sind (vgl. ...). “409

Die Wahrung der Grenzen dieses Beurteilungsspielraums unterliegt allerdings gerichtlicher Überprüfung. Das betrifft auch die Sachverhaltsdarstellung der Vollzugsanstalt. Hieraus ergibt sich als Anforderung des Grundrechtsschutzes die Pflicht der Vollzugsanstalt, die Anordnung besonderer Sicherungsmaßnahmen und deren Gründe unverzüglich bekanntzugeben und schriftlich zu dokumentieren.

408 BVerfG II/2, Beschluss vom 19.10.1993 - 2 BvR 1778/93 -, juris; um welche Sicherungsmaßnahmen es ging, ist dem Beschluss nicht zu entnehmen.

409 BVerfG II/2, Beschluss vom 24. Januar 2008 - 2 BvR 1661/06 -, juris. 
- „Der Beurteilungsspielraum entbindet die Gerichte jedoch nicht von ihrer rechtsstaatlich fundierten Prüfungspflicht (vgl. für die Gewährung von Vollzugslockerungen BVerfG, Beschlüsse der 2. Kammer des Zweiten Senats vom 12. November 1997 - 2 BvR 615/97 -, NStZ-RR 1998, S. $121<122>$; und vom 1. April 1998 - 2 BvR 1951/96 -, StV 1998, S. $436<437>$ ). Im Hinblick auf die verfahrensrechtlichen Gehalte der betroffenen Grundrechte (vgl. BVerfGE 52, $214<219$ ff.>; 70, $297<308$ ff. $>$; BVerfG, Beschlüsse der 2. Kammer des Ersten Senats vom 2. Mai 1994 - 1 BvR 549/94 -, NJW 1994, S. 1719 f.; und vom 8. September 1997 - 1 BvR 1147/97 -, NJW 1998, S. 295 f.; Beschluss der 2. Kammer des Zweiten Senats vom 1. April 1998, a.a.O.) haben die Gerichte vor einer Bestätigung der durch die Anstalt getroffenen Anordnungen die verfügbaren Erkenntnismittel auszuschöpfen und die von der Anstalt ihrer Gefahrenprognose zugrunde gelegten Sachverhaltsangaben zu überprüfen, um auf dieser Grundlage die - in der Untersuchungshaft besonders strikt zu beachtende - VerhältnismäBigkeit der getroffenen Anordnungen beurteilen zu können (vgl. BVerfG, Beschluss der 2. Kammer des Zweiten Senats vom 13. April 1999 - 2 BvR 827/98 -, StV 1999, S. $551<552$ f.>).

Bereits die Verfügung vom 19. Juni 2006, mit der der Vorsitzende Richter die Anordnung der besonderen Sicherungsmaßnahmen genehmigt und sich so zu eigen gemacht hat (vgl. ...), wird diesen verfassungsrechtlichen Anforderungen nicht gerecht.

Der beigezogenen Verfahrensakte ist nicht zu entnehmen, dass die Entscheidung, wie geboten (vgl. BVerfG, Beschluss der 2. Kammer des Zweiten Senats vom 6. November 2007 - 2 BvR 1136/07 -, www.bverfg.de, Rn. 33 ; ...), im Anschluss an die fernmündliche Genehmigung unverzüglich schriftlich niedergelegt und dem Beschwerdeführer oder dessen Bevollmächtigtem bekannt gegeben worden wäre. ... Damit sind die zum Zeitpunkt der Entscheidung zugrundegelegten Tatsachen und die hierauf bezogenen Erwägungen des Haftrichters schon nicht hinreichend nachvollziehbar.“"410

Werden schwer eingreifende besondere Sicherungsmaßnahmen wie die Unterbringung in einem besonders gesicherten Haftraum im Hinblick auf eine psychische Ausnahmesituation angeordnet, wie etwa wegen einer Gefahr selbstschädigenden Verhaltens, so ist eine sachverständige Explo-

410 BVerfG II/2, Beschluss vom 24. Januar 2008 - 2 BvR 1661/06 -, juris. 
ration zu veranlassen und zu klären, ob ausreichend versucht wurde, die erforderliche Dauer des Eingriffs durch Maßnahmen der psychosozialen Betreuung zu begrenzen.

- „Unabhängig davon kann im Übrigen ausgeschlossen werden, dass der Entscheidung eine den verfassungsrechtlichen Anforderungen genügende Sachverhaltsaufklärung vorausgegangen und auf dieser Grundlage eine einzelfallbezogene Verhältnismäßigkeitsprüfung durchgeführt worden ist. Der Vorsitzende Richter hat es insbesondere versäumt, eine umgehende Exploration des Beschwerdeführers durch den konsiliarisch in der Justizvollzugsanstalt tätigen Psychiater zu veranlassen, um die von der Anstalt angenommene akute Neigung des Beschwerdeführers zu selbstschädigendem Verhalten einer sachverständigen Begutachtung zuzuführen. ....Es ist schließlich nicht ersichtlich, dass sich der Haftrichter über - in der schriftlichen Stellungnahme der Justizvollzugsanstalt nicht dokumentierte - Versuche informieren ließ, eine Stabilisierung des psychischen Zustands des Beschwerdeführers durch psychosoziale Betreuungsmaßnahmen zu fördern und damit die Dauer der schwer eingreifenden Sicherungsmaßnahmen auf das unabweisbar Erforderliche zu begrenzen. " 411

Bei Anordnung kombinierter besonderer Sicherungsmaßnahmen ist die Verhältnismäßigkeit für jede einzelne Maßnahme zu klären. So bedürfen bei einer Unterbringung im besonders gesicherten Haftraum auch die näheren Modalitäten, etwa hinsichtlich der Ausstattung mit Kleidung, sowie begleitende Maßnahmen der Überwachung der Prüfung.

- „Weiterhin ist nicht ersichtlich, dass der telefonisch ausgesprochenen Genehmigung konkrete, auf die Umstände des Einzelfalls bezogene Erwägungen zur Notwendigkeit der im Einzelnen gegenüber dem Beschwerdeführer verhängten Sicherungsmaßnahmen zugrunde gelegen hätten. Der Hinweis in der durch den Vorsitzenden in Bezug genommenen Stellungnahme der Justizvollzugsanstalt, es handele sich um die „allgemein üblichen Vorgaben" für die Unterbringung im besonders gesicherten Haftraum, reicht insoweit jedenfalls nicht aus. Näherer Prüfung und Erörterung durch den Haftrichter hätte etwa bedurft, ob eine Aushändigung reißfester Textilien an den Beschwerdeführer als milderes, zur Verhinderung selbstschädigender Handlungen gleich ge-

411 BVerfG II/2, Beschluss vom 24. Januar 2008 - 2 BvR 1661/06 -, juris. 
eignetes Mittel in Betracht gekommen wäre, und ob nicht, nachdem bereits sämtliche gefährdenden Gegenstände aus dem besonders gesicherten Haftraum entfernt worden waren, auch eine lediglich akustische beziehungsweise gelegentliche visuelle Überwachung des Beschwerdeführers ausreichend gewesen wäre. Soweit gemäß den Angaben der Justizvollzugsanstalt aufgrund des Ausfalls der Infrarotfunktion der Überwachungskamera eine - schon nach Nr. 63 Abs. 1 Nr. 2 UVollzO unzulässige - unabgeschirmte Beleuchtung des Haftraums auch während der Nacht als erforderlich hätte angesehen werden können, wären im Übrigen die Gründe für das Unterbleiben einer umgehenden Reparatur in Erfahrung zu bringen gewesen." ${ }^{\text {412 }}$

Die Prüfungsanforderungen verschärfen sich bei längerer Dauer der Maßnahmen.

- „Die erneute Bestätigung der Unterbringung in einem besonders gesicherten Haftraum ohne gefährdende Gegenstände und mit Videoüberwachung mehr als zwei Wochen nach deren Beginn ohne Einholung eines psychiatrischen Gutachtens über den psychischen Zustand des Beschwerdeführers wird den eingangs dargestellten verfassungsrechtlichen Anforderungen auch deshalb nicht gerecht, weil das Gericht zu berücksichtigen gehabt hätte, dass besondere Sicherungsmaßnahmen, die über einen längeren Zeitraum aufrecht erhalten bleiben, verschärften Prüfungsanforderungen begegnen (vgl. BVerfG, Beschluss der 2. Kammer des Zweiten Senats des Bundesverfassungsgerichts vom 6. Februar 1996 - 2 BvR 2533/95, 2 BvR 2534/95 -, juris; und vom 13. April 1999 - 2 BvR 827/98 -, StV 1999, S. $551<552>$ ).“413

An einer gebotenen unverzüglichen Einholung nachträglicher richterlicher Zustimmung fehlt es, wenn für eine besondere Sicherungsmaßnahme, mit deren Durchführung freitagnachmittags um 15 Uhr begonnen wurde, die Zustimmung erst am nachfolgenden Montagvormittag einzuholen versucht wird. Insoweit liegt eine Dokumentationslast bei der Anstalt.

- „Lediglich ergänzend weist die Kammer darauf hin, dass das Vollzugspersonal es versäumt hat, unverzüglich - das heißt ohne schuldhaftes

412 BVerfG II/2, Beschluss vom 24. Januar 2008 - 2 BvR 1661/06 -, juris.

413 BVerfG II/2, Beschluss vom 24. Januar 2008 - 2 BvR 1661/06 -, juris. 
Zögern (vgl. § 121 Abs. 1 Satz 1 BGB) - die nachträgliche Zustimmung des Richters gemäß $§ 119$ Abs. 6 Satz 3 StPO, Nr. 62 Abs. 3 Satz 3 UVollzO zu den am 16. Juni 2006 vorläufig angeordneten Sicherungsmaßnahmen einzuholen (vgl. ....). Der zuständige Richter wurde erst am Montagvormittag, 19. Juni 2006, über den Sachverhalt informiert und erteilte seine Zustimmung zu den angeordneten Maßnahmen; eine frühere Kontaktaufnahme war nach den Angaben der Justizvollzugsanstalt aufgrund fehlender dienstlichen Erreichbarkeit des Richters am Freitagabend und am Wochenende nicht möglich. Mit der Durchführung der Maßnahme wurde jedoch bereits am Freitag, 16. Juni 2006 gegen 15.00 Uhr begonnen; für den - nicht dokumentierten - Versuch einer Kontaktaufnahme jedenfalls im Laufe des Nachmittags hätte mithin ausreichend Zeit bestanden."“414

\section{Haftraumverhältnisse}

Hinsichtlich der Haftraumbedingunen folgen aus Art. 1 Abs. 1 GG für die Untersuchungshaft keine grundsätzlich anderen Anforderungen als für die Strafhaft (BVerfG I/1, Beschluss vom 7.11.2011 - 1 BvR 1403/09 -, juris). Die für den Strafvollzug entwickelten verfassungsrechtlichen Anforderungen an Haftraumgröße und -ausstattung (B.XXVIII.1.) sind daher auf den Untersuchungshaftvollzug grundsätzlich übertragbar (s. bereits D.I.1.).

Für die Annahme der Übertragbarkeit trotz unterschiedlicher Möglichkeiten des Aufenthalts außerhalb des Haftraums ist allerdings auch die im Verhältnis zur Strafhaft typischerweise nur kurze Dauer der Untersuchungshaft von Bedeutung; bei atypischer Dauer der Untersuchungshaft könnte daher etwas anderes gelten.

- „Die Bodenfläche des Haftraums entspricht noch den Mindestanforderungen im Strafvollzug (vgl. ...). Selbst unter Berücksichtigung des Umstandes, daß ein Strafgefangener - anders als der Beschwerdeführer - regelmäßig Gelegenheit zum Aufenthalt in anderen Räumen hat, geben die zitierten Werte auch Anhaltspunkte für die Untersuchungshaft, da diese regelmäßig nur eine vergleichsweise kurze Zeit andauert. Der Ausschluß von Gemeinschaftsveranstaltungen und der Arbeit au-

414 BVerfG II/2, Beschluss vom 24. Januar 2008 - 2 BvR 1661/06 -, juris. 
Berhalb des Haftraums vermögen daher trotz der geringen Größe des Haftraums einen Verstoß gegen das Gebot der Achtung der Menschenwürde (Art. 1 Abs. 1 GG) jedenfalls derzeit nicht zu begründen. Der Ausschluß von Gemeinschaftsveranstaltungen und der Arbeit außerhalb des Haftraums vermögen daher trotz der geringen Größe des Haftraums einen Verstoß gegen das Gebot der Achtung der Menschenwürde (Art. 1 Abs. 1 GG) jedenfalls derzeit nicht zu begründen.

$\mathrm{Ob}$ die mit zunehmender Dauer der Haft wachsende Belastung des Beschwerdeführers durch die Sicherungsvorkehrungen zu einem späteren Zeitpunkt eine andere Beurteilung gebieten könnte, bedarf im vorliegenden Stadium des Ermittlungsverfahrens keiner Entscheidung. “415

Eine allgemeine nächtliche Stromabschaltung in der Untersuchungshaft war jedenfalls auf der Grundlage des $\S 119$ Abs. 3 StPO a.F. nicht zulässig (vgl. BVerfGK 13, 163<163>). Jedenfalls der Ausschluss des nächtlichen Rundfunkempfangs durch die Unterbrechung der Stromzufuhr berührt die durch Art. 5 Abs. 1 Satz 1 GG geschützte Informationsfreiheit. Soweit dieses speziellere Grundrecht nicht einschlägig ist, wird jedenfalls in das Recht auf freie Entfaltung der Persönlichkeit (Art. 2 Abs. 1 GG) eingegriffen (vgl. BVerfGK 13, $163<164>$ ).

Soweit der gebotenen Berücksichtigung der Umstände des Einzelfalls (dazu näher D.I.2.a) und D.I.3.) technische Hindernisse entgegenstehen, sind die technischen Gegebenheiten ihrerseits daraufhin zu überprüfen, ob sie mit den verfassungsrechtlichen Anforderungen an eine hinreichende Austattung der Vollzugsanstalten vereinbar sind.

- „Die Berufung der Anstalt darauf, dass die Stromversorgung in der Haftanstalt nur stockwerksweise an- oder abgeschaltet werden könne, gab Anlass, zu prüfen, ob ein derartiger technischer Zustand mit der grundsätzlich gebotenen Ausrichtung eingreifender Maßnahmen nach $\S 119$ Abs. 3 StPO auf den konkreten Einzelfall (vgl.BVerfGE 15, 288 $<297>$; $35,5<11>$ ) und mit der Verpflichtung vereinbar ist, bei Maßnahmen genereller Art gegenüber Untersuchungsgefangenen dem Grundsatz der Verhältnismäßigkeit dadurch Rechnung zu tragen, dass im Einzelfall Ausnahmen zugelassen werden, soweit dies ohne konkrete Gefährdung der in $\S 119$ Abs. 3 StPO genannten Interessen möglich ist (vgl. BVerfGE 15, $288<294 \mathrm{f}$.>; 34, $384<398,400>$; 34, 384

415 BVerfG II/2, Beschluss vom 19.10.1993 - 2 BvR 1778/93 -, juris. 
$<398>$; 42, $95<102>$ ). Auch damit hat das Gericht sich nicht auseinandergesetzt. Seine Feststellung, eine Ausnahme für den Beschwerdeführer gemäß Nr. 54 Abs. 2 der Untersuchungshaftvollzugsordnung (UVollzO) sei schon aus technischen Gründen nicht möglich, geht an der Frage vorbei, inwieweit die Anstalt berechtigt sein kann, sich auf technische Unmöglichkeiten zu berufen, die technisch problemlos behebbar wären. Da der Staat einerseits verpflichtet ist, die Vollzugsanstalten in der zur Wahrung der Grundrechte erforderlichen Weise auszustatten (vgl.BVerfGE 40, $246<284>$; BVerfG, Beschluss der 2. Kammer des Zweiten Senats vom 25. Juli 1994 - 2 BvR 806/94 -, a.a.O., S. $1478<1479$ f. $>$ ), andererseits aber die Wahrung der Grundrechte keinen unbegrenzten, unzumutbaren Aufwand // erfordert (vgl.BVerfGE 34, $369<380$ f.>; 34, $384<402>$; 42, $95<100$ f. $>$ ), ist dies eine Frage der Verhältnismäßigkeit der Beeinträchtigungen, die von dem gegebenen technischen Zustand ausgehen, und - was auf dasselbe hinausläuft - der Zumutbarkeit des Mitteleinsatzes für technische Veränderungen. Eine den verfassungsrechtlichen Anforderungen entsprechende Beantwortung dieser Frage hätte nähere Informationen erfordert, die das Gericht nicht eingeholt hat. Die vom Ministerium in seiner Stellungnahme zur Verfassungsbeschwerde mitgeteilten Renovierungspläne zeigen, dass nähere Informationen zur Beschaffenheit der Elektrotechnik in der Anstalt und zum Aufwand für Veränderungen, die es erlauben würden, dem Grundsatz der Verhältnismäßigkeit besser Rechnung zu tragen, ohne weiteres verfügbar gewesen wären, und dass aus dortiger Sicht die technischen Verhältnisse in praktikabler und zumutbarer Weise veränderbar sind.“416

Grundrechte des Untersuchungsgefangenen sind verletzt, wenn bei der Beurteilung der Verhältnismäßigkeit von Grundrechtseingriffen unberücksichtigt bleibt, welches Gewicht einer Beeinträchtigung angesichts der besonderen psychischen Belastungen durch die Untersuchungshaft ausgesetzt sind.

- „In der Entscheidung des Oberlandesgerichts fehlt es auch an jeder erkennbaren, gewichtenden Berücksichtigung des Umstandes, dass die Maßnahme Grundrechte des Beschwerdeführers nicht unerheblich beeinträchtigt. Auch wenn von der Unterbrechung der Stromzufuhr aus- 
schließlich Nachtstunden betroffen sind, in denen üblicherweise geschlafen wird, kann der Eingriff nicht als völlig geringfügig angesehen werden. Die Möglichkeit, Rundfunk zu empfangen und sich bei Licht zu beschäftigen - etwa zu lesen oder zu schreiben - und die Möglichkeit, dies auch in den Nachtstunden zu tun, ist gerade für einen Untersuchungsgefangenen von besonderer Bedeutung. Untersuchungshaft ist für die Betroffenen hochgradig belastend. Untersuchungsgefangene sind in besonderem Maße - noch mehr als andere Inhaftierte - suizidgefährdet (vgl. ...). Es liegt auf der Hand, dass die in der Untersu- // chungshaft rechtlich möglichen und notwendigen besonderen Kontaktbeschränkungen, das Warten auf den Strafprozess und die besondere Ungewissheit der Haftdauer nicht nur mit Risiken für die psychische Stabilität verbunden sind, sondern auch den Schlaf-Wach-Rhythmus stören können, und dass es daher gerade in dieser Lage eine besondere zusätzliche Belastung darstellt, nachts weder elektrische Geräte noch auch nur das Licht einschalten zu können. Die generelle Stromabschaltung in den bezeichneten Nachtstunden bedurfte daher sorgfältiger Prüfung auch unter dem Gesichtspunkt der Verhältnismäßigkeit im engeren Sinne. Dem Vorbringen der Justizvollzugsanstalt und den Gründen der hierauf gestützten Entscheidung des Oberlandesgerichts sind Sachverhaltsfeststellungen und eine Abwägung, die die Beurteilung der angegriffenen Maßnahme als mit Blick auf die Grundrechte des Beschwerdeführers angemessen rechtfertigen könnten, nicht $\mathrm{zu}$ entnehmen (vgl. ...). “417

Angesichts eines gesetzlich vorgesehenen Anspruchs auf Einzelunterbringung sind Untersuchungsgefangenen auch Beschränkungen, die an eine Mehrfachunterbringung anknüpfen, jedenfalls bei unfreiwilliger Unterbringung in mehrfach belegten Hafträumen nicht ohne Weiteres zumutbar (vgl., nächtliche Stromabschaltung betreffend, BVerfGK 13, 163 $<170>$ ).

XI. Urinkontrollen

Die Anordnung einer Urinkontrolle war schon auf der Grundlage des $\S 119$ Abs. 3 StPO jedenfalls beim Vorliegen konkreter Anhaltspunkte für

417 BVerfGK 13, 163 (169f.). 
einen Betäubungsmittelkonsum des betroffenen Gefangenen verfassungsrechtlich nicht zu beanstanden.

- „Für die Auslegung des $\S 119$ Abs. 3 StPO und die Prüfung der Voraussetzungen für eine Beschränkung nach dieser Bestimmung ist entscheidend, dass der Grundsatz der Verhältnismäßigkeit, der den Vollzug der Untersuchungshaft in besonderem Maße beherrschen muss (vgl. BVerfGE 19, $342<347>$ ), eine Abwägung aller Umstände des Einzelfalles gebietet. Beschränkungen sind danach nur zulässig, wenn sie erforderlich sind, um eine reale Gefahr für die in $\S 119$ Abs. 3 StPO genannten öffentlichen Interessen abzuwehren, und dieses Ziel nicht mit weniger eingreifenden Maßnahmen erreicht werden kann (vgl. BVerfGE 35, $5<9$ f.>; 35, $311<321>$ ). Die Auferlegung einer Beschränkung ist nach $\S 119$ Abs. 3 StPO nicht schon dann zulässig, wenn ein möglicher Missbrauch eines Freiheitsrechts nicht völlig auszuschließen ist. Vielmehr müssen konkrete Anhaltspunkte für eine Gefährdung des Haftzwecks oder der Ordnung in der Anstalt vorliegen (vgl. BVerfGE 35, $5<10>$; 42, $234<236>$; 57, $170<177>$; BVerfG, Beschluss der 2. Kammer des Zweiten Senats vom 20. Juni $1996-2$ BvR 634/96 -, StV 1997, S. $257<258>$ ).

Bei Zugrundelegung dieses Maßstabs ist die Feststellung der angegriffenen Entscheidungen, die Anordnung der Abgabe einer Urinprobe könne auf $\S 119$ Abs. 3 StPO gestützt werden, von Verfassungs wegen nicht zu beanstanden. Amtsgericht und Landgericht haben die Notwendigkeit von Urinkontrollen im Vollzug von Untersuchungshaft nachvollziehbar mit den schwerwiegenden Gefahren begründet, die von dem Konsum von Betäubungsmitteln für die Sicherheit und Ordnung der Anstalt ausgehen. Die Anordnung einer Urinkontrolle begegnet daher jedenfalls beim Vorliegen konkreter Anhaltspunkte für einen Betäubungsmittelkonsum des betroffenen Gefangenen keinen verfassungsrechtlichen Bedenken (...).“418

Das verfassungsrechtliche Verbot eines Selbstbezichtigungszwangs stand dem nicht entgegen.

- „Eine andere Beurteilung ist auch nicht unter dem Gesichtspunkt des aus Art. 2 Abs. 1 i.V.m. Art. 1 Abs. 1 GG abgeleiteten Verbots eines Selbstbezichtigungszwangs (vgl. BVerfGE 55, $144<150>$; 56, 37

418 BVerfGK 13, 378 (380). 
$<41$ f. $>$ ) geboten. Es kann dahinstehen, ob dieses Verbot durch die Anordnung der Abgabe einer Urinprobe berührt wird. Auch bejahendenfalls würde daraus für den vorliegenden Fall nicht die Unzulässigkeit der Anordnung, sondern nur die Unzulässigkeit der Verwertung der gewonnenen Probe jedenfalls in einem Strafverfahren folgen; denn die Anordnung erfolgte hier nicht, um den Untersuchungsgefangenen einer Straftat zu überführen, sondern zur Abwehr von Gefahren für Dritte (vgl. BVerfGE 56, 37 <49 f.>; BVerfG, Beschluss der 2. Kammer des Zweiten Senats vom 21. April 1993 - 2 BvR 930/92 -, NStZ 1993, S. 482; OLG Oldenburg, a.a.O.; krit. dazu Pollähne, StV 2007, S. 89 $<90$ f. $>$; zur hier nicht entscheidungsbedürftigen Frage eines Verwertungsverbots auch in vollzugsrechtlichen Disziplinarverfahren verneinend HansOLG Hamburg, Beschluss vom 2. März $2004-3$ Vollz (Ws) 128/03 -; juris; bejahend Gericke, StV 2003, S. $305<307>$ ).

Entgegen der Auffassung des Beschwerdeführers waren vorliegend nicht nur Anhaltspunkte für einen Kontrollbedarf innerhalb der Anstalt, sondern auch in seiner Person liegende konkrete Anhaltspunkte für die Gefahr eines fortgesetzten Betäubungsmittelkonsums in der Haft vorhanden. Der Beschwerdeführer hatte im Rahmen der polizeilichen und richterlichen Beschuldigtenvernehmung eingeräumt, regelmäßig Marihuana und gelegentlich Kokain zu konsumieren, und wurde bei der Eingangsuntersuchung positiv auf THC und Kokain getestet. Überdies entstammten die dem Beschwerdeführer zur Last gelegten Taten dem Bereich der Betäubungsmitteldelinquenz. Des Hinzutretens weiterer Umstände - etwa eines dem Beschwerdeführer zuzuordnenden Drogenfundes oder bei ihm gegebener Anzeichen für einen Rauschzustand - bedurfte es angesichts dieser Anhaltspunkte nicht, um die Anordnung der Kontrollmaßnahme zu rechtfertigen." “419

XII. Arbeitsentgelt

Dass Arbeit von Untersuchungsgefangenen nicht in gleicher Weise entlohnt wird wie die Pflichtarbeit von Strafgefangenen, verletzt weder den Gleichheitsgrundsatz noch die Unschuldsvermutung. 
„Art. 3 Abs. 1 GG gebietet, Gleiches gleich und Ungleiches seiner Eigenart entsprechend verschieden zu behandeln (BVerfGE 42, $64<72>$; 71, $255<271>$; stRspr). Eine unterschiedliche Behandlung muss sich daher auf Unterschiede in den Sachverhalten zurückführen lassen, die es rechtfertigen, sie als im Hinblick auf die fragliche Behandlung ungleich anzusehen. Art. 3 Abs. 1 GG ist verletzt, wenn für eine vom Gesetzgeber vorgenommene Differenzierung ein einleuchtender Grund nicht auffindbar ist (vgl. BVerfGE 42, $374<388>$; 76, $256<329>$; stRspr). Innerhalb dieser Grenzen ist es Sache des Gesetzgebers, diejenigen Sachverhalte auszuwählen, an die er dieselbe Rechtsfolge knüpft, die er also im Rechtssinn als gleich ansehen will (BVerfGE 75, $108<157>$; $103,310<318>$ ).

Nach diesen Maßstäben hat das Kammergericht zu Recht angenommen, es liege kein Verstoß gegen den allgemeinen Gleichheitssatz darin, dass nach dem gesetzgeberischen Regelungskonzept die Arbeit von erwachsenen Untersuchungsgefangenen nicht in gleicher Weise entgolten wird wie die Arbeit von Strafgefangenen. Die vorgenommene Differenzierung knüpft an Unterschiede in der Funktion von Untersuchungs- und Strafhaft an, deren Berücksichtigung bei der Bemessung des Arbeitsentgelts im politischen Ermessen des Gesetzgebers liegt. Die Untersuchungshaft nach den Grundsätzen des Erwachsenenvollzugs dient der Sicherung des Strafverfahrens und einer eventuellen Strafvollstreckung und ist auf diesen Sicherungszweck beschränkt. Für dessen Verwirklichung kommt es nicht darauf an, dass der Untersuchungsgefangene Arbeit verrichtet. Untersuchungsgefangene sind daher, anders als Strafgefangene, jedenfalls im Erwachsenenvollzug zur Arbeit nicht verpflichtet (...// ...).

Der Strafvollzug ist dagegen vom verfassungsrechtlich verankerten Resozialisierungsgebot geprägt (vgl. BVerfGE 98, 169, <200>). ... Mit Rücksicht auf die unterschiedliche Bedeutung, die der Arbeit nach der Zweckbestimmung von Untersuchungs- und Strafhaft zukommt, war der Gesetzgeber nicht gehalten, die von erwachsenen Untersuchungsgefangenen geleistete Arbeit in gleicher Weise wie die Arbeit von Strafgefangenen anzuerkennen (vgl. ...).

Eine andere verfassungsrechtliche Beurteilung folgt auch nicht aus der für Untersuchungsgefangene geltenden Unschuldsvermutung. Die rechtsstaatliche Unschuldsvermutung schützt den Beschuldigten vor Nachteilen, die Schuldspruch oder Strafe gleichkommen, denen aber kein rechtsstaatliches prozessordnungsgemäßes Verfahren zur Schuld- 
feststellung und Strafbemessung vorausgegangen ist (vgl. BVerfGE 74, $358<371>$; 82, $106<114 \mathrm{f}$.>) Aus ihr folgt - auch bezüglich der Bemessung des Arbeitsentgelts - nicht, dass die Situation des Untersuchungsgefangenen der des Strafgefangenen angeglichen werden müsste. Dem Untersuchungsgefangenen wird mit der Bemessung des Entgelts für von ihm geleistete Arbeit weder Schuld zugewiesen noch eine Strafe auferlegt.“" 420 